RESEARCH

SERIES

NUMBER 108

JULY 2020

\section{EXPLORING THE SHORT-RUN IMPLICATIONS OF THE COVID-19 PANDEMIC ON AFFORDABILITY IN THE IRISH PRIVATE RENTAL MARKET}

CONOR O'TOOLE, RACHEL SLAYMAKER, KIERAN MCQUINN, CATHAL COFFEY AND EOIN CORRIGAN

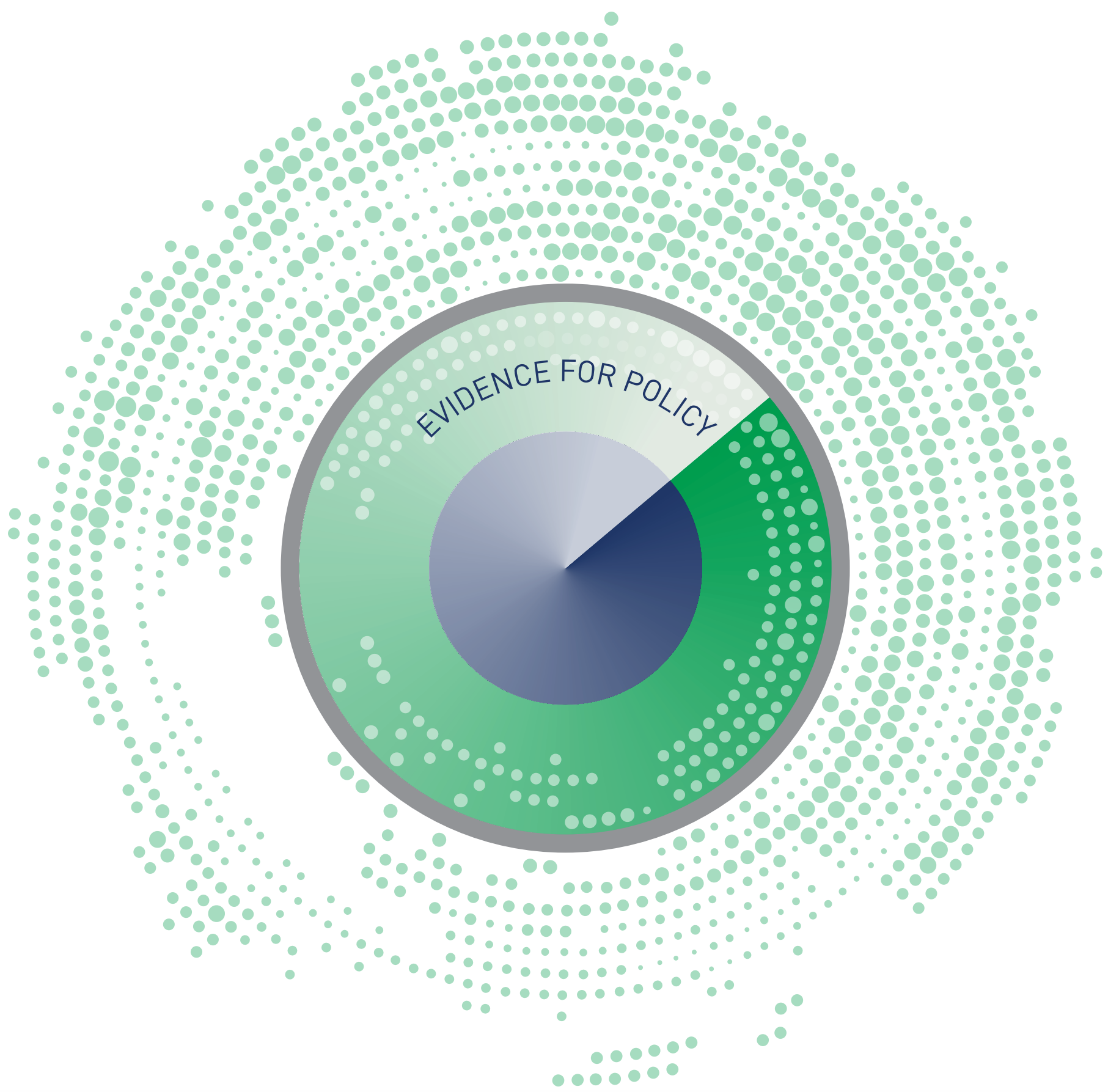




\title{
EXPLORING THE SHORT-RUN IMPLICATIONS OF THE COVID-19 PANDEMIC ON AFFORDABILITY IN THE IRISH PRIVATE RENTAL MARKET
}

\author{
Conor O'Toole ${ }^{a}$, Rachel Slaymakera, Kieran McQuinn ${ }^{a}$, Cathal Coffey ${ }^{a}$, Eoin \\ Corrigan $^{b}$ \\ ${ }^{a}$ Economic and Social Research Institute \\ ${ }^{b}$ Department of Housing, Planning and Local Government
}

July 2020

ESRI Research Series No. 108

https://doi.org/10.26504/rs108.pdf

ISBN: 978-0-7070-0534-8

This research was completed under the Joint Research Programme on Housing Economics between the ESRI and the Department of Housing, Planning and Local Government. The views expressed in this paper are those of the authors and they should not be regarded as an official position of the Department of Housing, Planning and Local Government. Results are based on analysis of strictly controlled Research Microdata Files provided by the Central Statistics Office (CSO). The CSO does not take any responsibility for the views expressed or the outputs generated from this research. 



\section{TABLE OF CONTENTS}

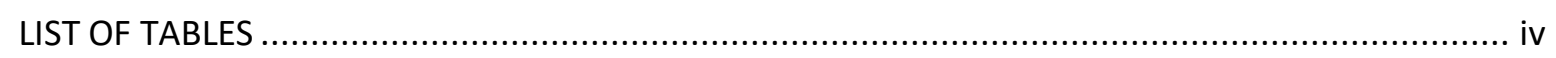

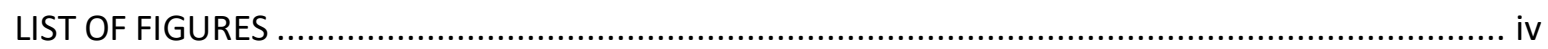

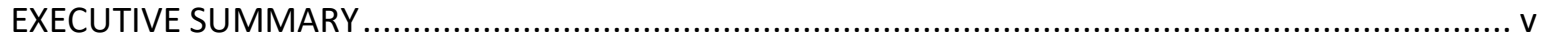

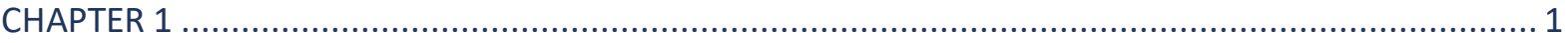

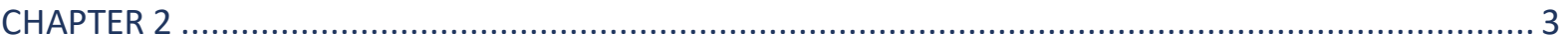

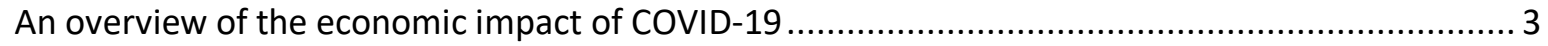

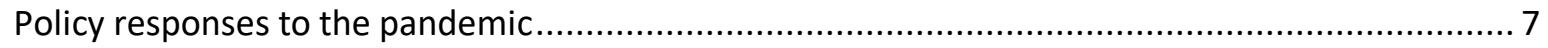

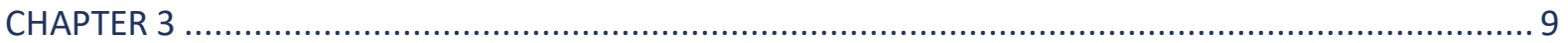

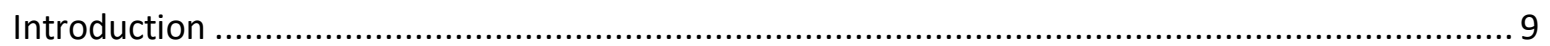

Which households are currently in the rental sector? ....................................................

An overview of affordability across private rental households ........................................... 13

Simulating the unemployment and labour-market shock ......................................... 15

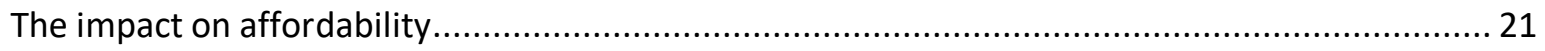

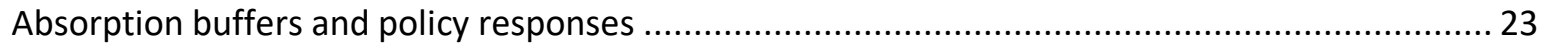

Pandemic-related changes to consumption bundles in the short run ............................... 23

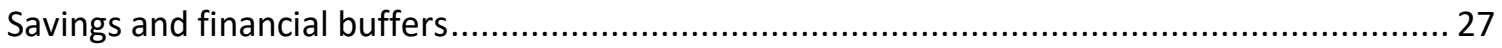

Rent Supplement as a housing cost tool........................................................... 29

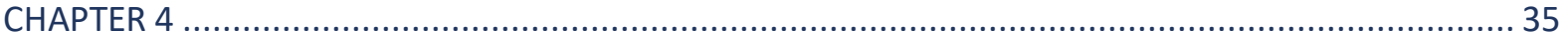

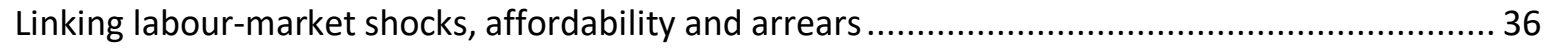

Measuring and modelling missed payments in the rental sector ....................................... 36

Scenarios for possible developments in missed payments............................................ 39

Pandemic-related specificities: a cautionary note on the modelling scenarios...................... 40

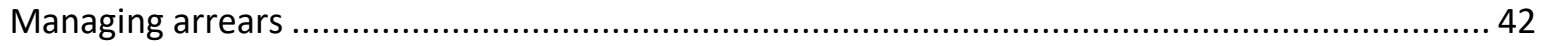

Addressing data gaps.................................................................................... 43

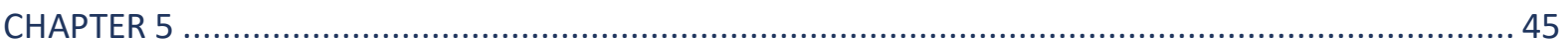

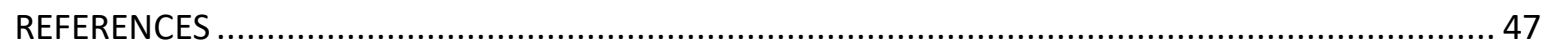

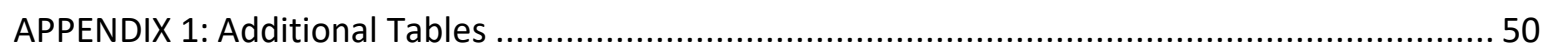

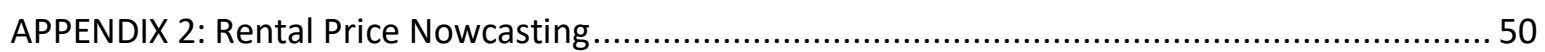




\section{LIST OF TABLES}

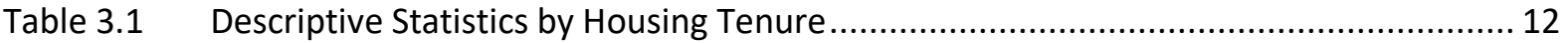

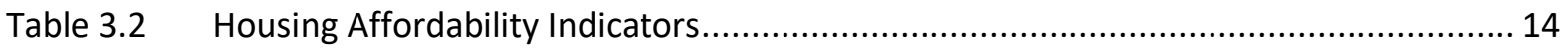

Table 3.3 Income and Affordability Measures for Private Renters ............................................ 15

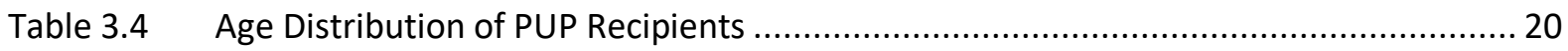

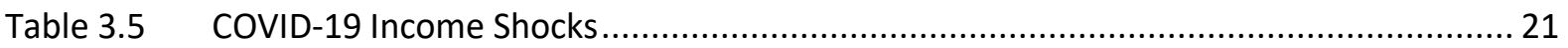

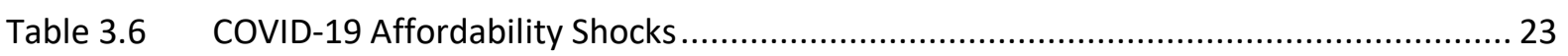

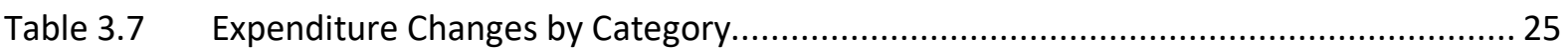

Table 3.8 Adjustment to Required Expenditure during Pandemic.............................................. 26

Table 3.9 Impact of Expenditure Reductions on Income Sufficiency Ratio Affordability Measure 26

Table 3.10 Impact of Rent Supplement on Affordability Outcomes ........................................... 33

Table 3.11 Rent Supplement (RS) Impact on Affordability Outcomes for RS Recipient Households34

Table 4.1 Determinants of Missed Rental Payments - Marginal Effects..................................... 39

Table 4.2 Predicted Missed Payments Rates - Model Approach .................................................. 40

Table A.1 SILC and HFCS Private Rental Sample Matching Comparison ...................................... 50

Table A.2 Median Rental Growth by NUTS3 Region 2018 and 2019 .......................................... 51

\section{LIST OF FIGURES}

Figure 2.1 GDP - 2019 and Scenarios for 2020 (\% annual Change) .......................................... 3

Figure 2.2 Unemployment by Quarter (\%) ....................................................................... 4

Figure 2.3 Retail Sales Index (Volume Adjusted) -Year-on-Year Change to March and April 2020.5

Figure 2.4 Credit and Debit Card Expenditure Data - March, April 2020 (Year-on-Year Change) .. 6

Figure 2.5 Inflation - Month-on-Month (\%)...................................................................... 7

Figure 3.1 Percentage of Households by Tenure and Income Distribution ................................ 10

Figure 3.2 Proportion of Workers on PUP, TWSS and Remaining in Work by Sector................... 16

Figure 3.3 Microsimulation - New Employment Status of Workers ........................................... 20

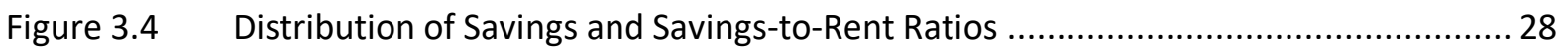

Figure 3.5 Percentage of Households Able to Cover Rent with Savings by No. of Months .......... 29

Figure 3.6 Number of Households on Income Supports including Rent Supplement $(, 000 \mathrm{~s}) \ldots . . . .31$

Figure 4.1 Trend in Rental and Mortgage Payment Difficulties ............................................. 36

Figure 4.2 Correlation between Missed Payments, Affordability and Unemployment ............... 38

Figure A.1 Distribution of Rental Price Growth Rates for 2018/2019 Property-Matched Sample 51 


\section{EXECUTIVE SUMMARY}

The COVID-19 pandemic represents the most severe and rapid shock to the Irish economy in modern times. This paper examines the short-run, three-month impact of the pandemic on rental affordability and missed payments for a specific cohort of the private rental sector in Ireland. It focuses on those households which, at the outset of the pandemic, were not in receipt of state rental supports such as the Housing Assistance Payment (HAP) or Rent Supplement (or paying a local authority rent). These households were deemed the most at risk of affordability challenges due to the high level of rents they were paying. In this report we classify such households as non-supported private renters. Unless otherwise stated, any reference to 'households' refers to this group.

\section{Main Findings}

\section{Key Findings on Affordability}

- Many non-supported private renters faced considerable affordability challenges prior to COVID-19; about one in three or approximately 70,000 households did not have sufficient income remaining after housing costs to cover a minimum standard of living expenditure before the pandemic. While the pandemic-related income shock for these households is likely to have been more severe than for the general population, the evidence suggests that, in the very short run (between mid-March and mid-June 2020), the unique and extraordinary circumstances of the current situation mean the affordability pressures are not likely to have worsened overall. Indeed, some households may be better off.

- This is due to the fact that short-run changes to expenditure and consumption, which came about mainly as a result of the public health restrictions, are likely to have outweighed the decline in incomes. Indeed, the income support provided through the Pandemic Unemployment Payment and the Temporary Wage Subsidy Scheme is significantly greater than the traditional income supports. We find that the share of households whose after-rent income is insufficient to purchase a minimum bundle of goods falls to just under one in five (from one in three); this decline equates to approximately 26,000 households.

- However, these are very short-term effects and unique to the current period in which households have been advised to stay at home and restrict movements. Many non-supported private renters face longer-term structural affordability pressures that are likely to worsen quickly as expenditure requirements (such as on transport and childcare) rebound quicker than incomes. Indeed, the COVID-19 labour-market shock has been heavily concentrated in sectors (such as accommodation and food) 
of the economy whose employees are more likely to be renters than homeowners. This will pose labour-market challenges for renters in the recovery if such sectors are slow to rebound. Any tapering of the income supports will thus have a disproportionate effect on this group.

\section{Key Findings on Missed Payments}

- Understanding the level of missed rental payments and arrears (both before and since the pandemic began) is exceedingly difficult given the absence of national, real-time data on missed payments. Survey data suggest that approximately one in ten non-supported rental households missed payments due to financial difficulties prior to the pandemic. ${ }^{1}$

- Given the unprecedented nature of the current pandemic, it is very difficult to estimate the trajectory of the actual rate of missed rental payments using historical relationships.

- Model estimates based on the relationship between affordability stress, unemployment and rental payment difficulties suggest that there is likely to be an increase in missed payments due to the income and particularly unemployment shocks faced by certain households. However, this increase in missed payments is likely to be tempered in the short run due to consumption expenditure falling more rapidly than incomes, which reduces the likelihood of missed payments for many households in the short term. Our model estimates suggest a moderate rise in missed payments due to the combination of these factors, from 9.8 to 10.8 per cent of households. Wider take-up of Rent Supplement could have a stronger role to play in shielding low and moderate-income households from housing affordability and payment difficulties.

- It must be noted that these scenarios are not able to account for the impact of the removal of eviction risk or any behavioural changes that may occur due to the specificities of the pandemic and are therefore subject to considerable uncertainty.

- There is a clear data gap in measuring missed payments in the current infrastructure that should be bridged for the rental sector in future. Such data are available on mortgage arrears from the Central Bank on a quarterly basis. The feasibility of a similar reporting of arrears cases in the rental sector should be explored.

\footnotetext{
${ }^{1}$ Missed payments refers to having missed one or more rental payments due to financial difficulties in the previous 12 months.
} 


\section{Introduction}

The COVID-19 pandemic represents the most rapid and severe economic shock to the Irish economy in living memory. The speed and scale of the disruptions to economic and social life are outside any experience, bar wartime. In conducting a scenario analysis, Allen-Coghlan et al. (2020) estimate that the economy could contract by between 9 and 17 per cent in 2020, depending on the epidemiological situation. The scale of the adjustment in the labour market is unprecedented; as of May 2020, approximately $1.14 \mathrm{~m}$ people or 46 per cent of the labour force are on unemployment benefits or other income-related policy supports. ${ }^{2}$ The swift introduction of COVID-19-specific income supports through the Pandemic Unemployment Payment (PUP) and the Temporary Wage Subsidy Scheme (TWSS) are providing considerable offset against income shocks for households. Nevertheless, many households have seen their incomes fall and face a period of heightened uncertainty.

The aim of this paper is to consider the short-run impact of these shocks on housing affordability and on the ability of households to make rental payments. Our focus is on a specific cohort of the private rental sector who are paying full market rents and are not in receipt of state allowances to cover housing costs. This narrows our work to a subset of all households in the private rental sector, as we exclude Housing Assistance Payment (HAP) tenancies and those on other supports. Many of these households have previously been found to have high housing costs (Corrigan et al., 2019) and many are thus likely to be vulnerable to changes in their financial circumstances. In this report, we class such households as non-supported private renters.

In this research, we use data from the Survey on Income and Living Conditions (SILC) to match the labour-market shock to Irish renter households. We then track a number of commonly cited measures of housing affordability before and during the COVID-19 shock to simulate how the pandemic has affected housing affordability for renters during the period in question. In particular, we look at the share of households for which rent accounts for more than 30 per cent of net income, and the share of households whose remaining income levels after the rent payment is insufficient to cover an acceptable minimum level of expenditure. ${ }^{34} \mathrm{We}$ then explore whether savings that households have and the specific changes to

\footnotetext{
${ }^{2}$ This refers to individuals on the Live Register, PUP or TWSS. Available at: https://statbank.cso.ie/px/pxeirestat/Statire/SelectVarVal/Define.asp?maintable=LRM20\&PLanguage=0

${ }^{3}$ We define minimum expenditure by matching types of households in SILC to the closest minimum expenditure basket from the Vincentian Partnership Minimum Expenditure Standard of Living (MESL) data. These data are available at www.budgeting.ie

${ }^{4} \mathrm{~A}$ threshold of 30 per cent is one of many affordability measures, for example some countries use 35 per cent limits. The question of what is a suitable measure of affordability is further discussed in Corrigan et al (2019).
} 
consumption bundles brought about by the pandemic offset the shock. We also review the extent to which Rent Supplement could act as a policy tool to offset affordability pressures for eligible households during the pandemic. Finally, we attempt to explore the likely scale of missed rental payments due to the labourmarket developments and changes in consumption.

A number of important assumptions underlie the analysis in this paper. First, this is a short-term analysis of the immediate impacts of the pandemic, covering the three-month period from the end of March onwards. Our analysis does not extend beyond this three-month timeframe and we do not take into consideration the longer-term affordability position of rental households. Second, we only consider workers who move onto either PUP or the TWSS; we do not consider the impact of any changes in hours or earnings of those not part of either scheme. We also assume no changes to non-employment incomes. Third, we treat PUP and TWSS payments as net income payments. While these payments will be taxable, any tax liability will be determined at the year end and will depend on the individual's earnings over the entire tax year. Our analysis is therefore done on a cashflow basis in an attempt to understand the immediate affordability challenges during this short-term analytical horizon.

The rest of this paper is structured as follows. Chapter 2 presents an overview of the economic impact of the pandemic to date, as well as the policy response. Chapter 3 examines the characteristics of non-supported private rental households, and the extent of their pre-COVID-19 housing affordability challenges, and uses a static microsimulation approach to model the impact of the COVID-19 labour-market shocks on rental affordability outcomes. It then examines whether (i) changes in consumption patterns, (ii) savings and (iii) the availability of Rent Supplement could help to offset the income shocks caused by the COVID-19 pandemic. Chapter 4 explores how affordability developments since the onset of the pandemic may translate into missed payments in the near term. Chapter 5 concludes and presents some policy implications. 


\section{Economic Impact and Policy Responses}

\section{AN OVERVIEW OF THE ECONOMIC IMPACT OF COVID-19}

The economic consequences of the pandemic have been far-reaching, swift and severe. Economic activity has experienced a marked decline, which has resulted in an unprecedented shock to international and domestic demand, the consequences of which have been mass unemployment and a major reduction in household consumption. In several sectors of the economy, economic activity has become either impossible or has been curtailed considerably, due to consumer caution, public health containment measures and social distancing guidelines.

In the most recent Quarterly Economic Commentary, Allen-Coghlan et al. (2020) document scenarios for the economic impact of the pandemic in 2020. They present three specific cases for economic activity for Ireland, taking into consideration: a) ongoing physical distancing to the end of the year (baseline), b) a second wave (severe) and c) successful disease suppression in quarter 4 (benign). They estimate that the reduction in GDP across these three scenarios will range from 9 per cent to greater than 17 per cent (Figure 2.1). This highlights the unprecedented scale and rapidity of the economic contraction associated with the COVID-19 pandemic.

\section{FIGURE 2.1 GDP - 2019 AND SCENARIOS FOR 2020 (\% ANNUAL CHANGE)}

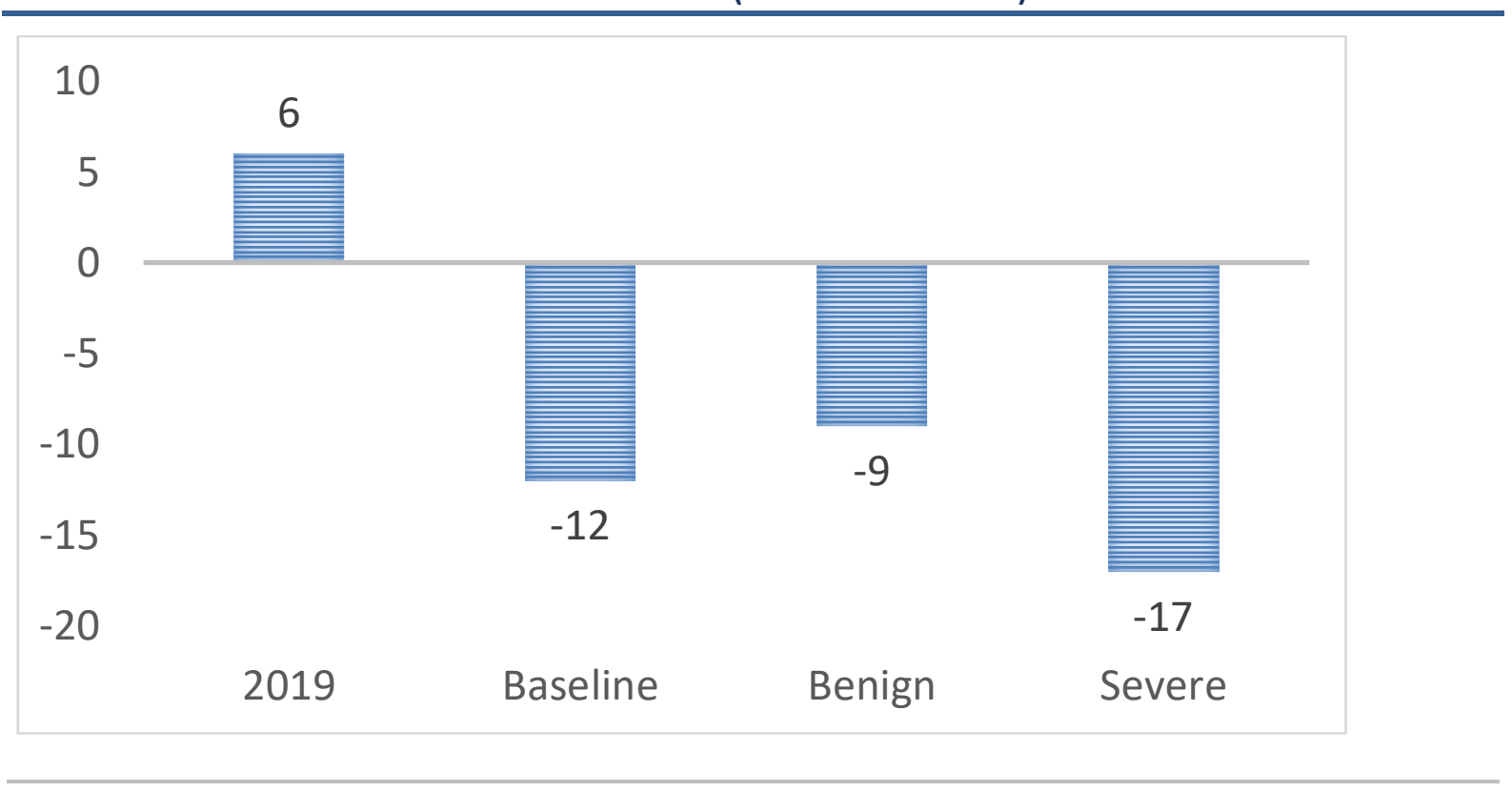


The impact of the pandemic on the labour market has been extreme and immediate. The unemployment rate has increased at an unprecedented speed. While we provide more detail on the labour-market shocks in subsequent chapters, it is insightful to consider the impact of the pandemic from a longer-term perspective. Figure 2.2 shows the average unemployment rate for Ireland from 1973 to present (quarterly); it can be seen that the unemployment rate is significantly higher now than at any period in recent history. Furthermore, the speed at which unemployment has escalated is without comparison over the period.

\section{FIGURE 2.2 UNEMPLOYMENT BY QUARTER (\%)}

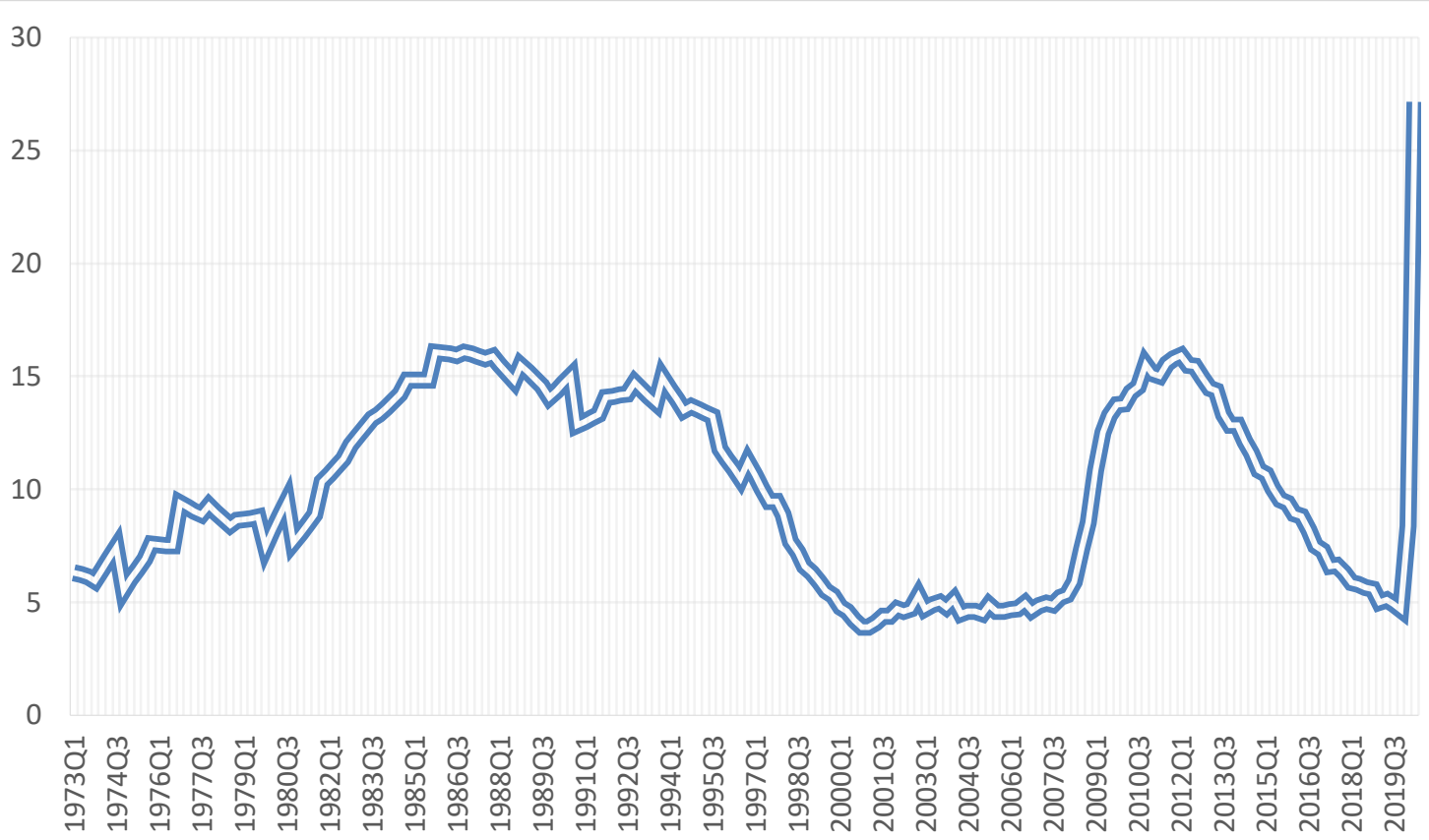

Source: Authors' Calculations.

Note: $\quad$ For the pandemic period, from March to May 2020, we have used the CSO adjusted pandemic unemployment series (rates of $18 \%, 28 \%, 26 \%$ respectively. Individuals receiving the Temporary Wage Subsidy Scheme are treated as employed. The Q1 figures for 2020 include the traditional unemployment figure for January and February with the March pandemic series. Q2 2020 is proxied by the average of April and May 2020.

A defining characteristic of the current pandemic has been a dramatic and rapid decline in consumer spending. A combination of a) households avoiding situations that may leave them open to infection risk; b) the extensive administrative restrictions on economic and social life required to 'flatten the curve', and c) the shocks to the labour market have all led to a major fall-off in household consumption.

The scale of the consumption shock can be observed from the CSO retail sales data. Figure 2.3 presents the year-on-year change in the Volume Adjusted Retail Sales Index for both March and April 2020. In March 2020, the overall Retail Sales Index 
was down 11 per cent year-on-year, and, as noted in Allen-Coghlan et al. (2020), down 13 per cent from the average in January and February 2020. This is noteworthy given that the widescale restrictions on commerce and social mobility did not come into operation until the end of March. The decline in the index for March suggests that households had already begun to modify their behaviour in advance of the lockdown measures introduced by the national authorities.

In April, the Retail Sales Index fell a further 34 per cent from the March level and was down nearly 44 per cent from April 2019. The extensive restrictions on economic life were fully operational through April. Therefore, these data provide a good indication as to how much economic activity was continuing throughout the lockdown.

FIGURE 2.3 RETAIL SALES INDEX (VOLUME ADJUSTED) - YEAR-ON-YEAR CHANGE TO MARCH AND APRIL 2020

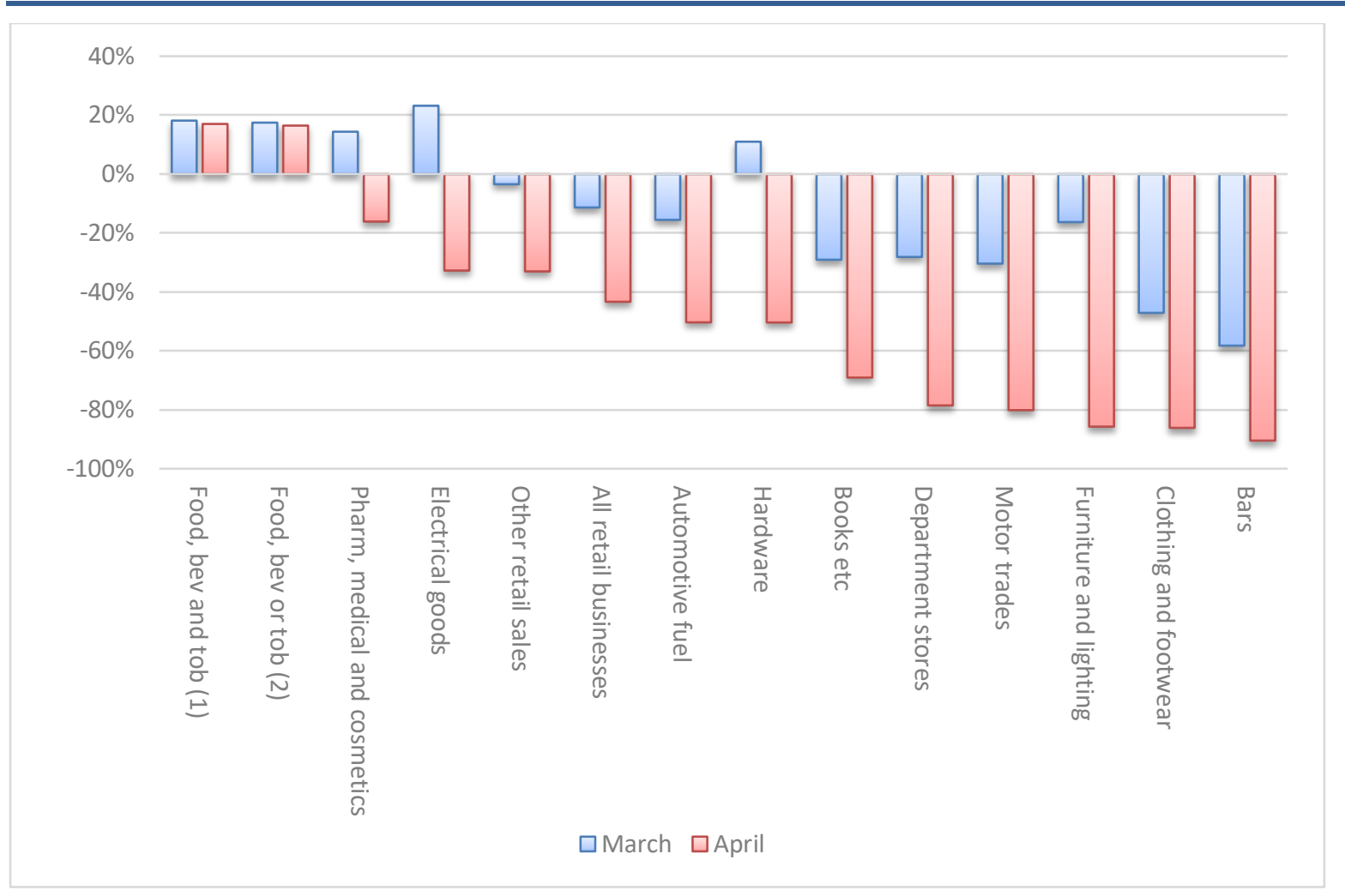

Source: Central Statistics Office.

One notable feature of the retail sales data is the variation across items in the scale of the decline. This has been documented in Coffey et al. (2020), who explore changes to household consumption at a granular level following the onset of the pandemic. The major declines have occurred in expenditure related to furniture, lighting, clothing and motor fuels, which are all down close to or above 80 per cent year-on-year in April. On the other hand, expenditure on food and beverages is up nearly 20 per cent year-on-year as households focus expenditure on food in the 
home. Recently, the CSO released retail sales data for May 2020 which show an increase of 28.4 per cent from the April low. However, retail sales continue to be 30 per cent lower on a year-on-year basis.

Given that the retail sales data concentrate solely on expenditure in retail businesses, more insight can be gleaned from the Central Bank of Ireland Credit and Debit Card Expenditure data, which provide insights into spending on services and entertainment. ${ }^{5}$ These data are presented in Figure 2.4 .

\section{FIGURE 2.4 CREDIT AND DEBIT CARD EXPENDITURE DATA - MARCH, APRIL 2020 (YEAR-ON-YEAR CHANGE)}

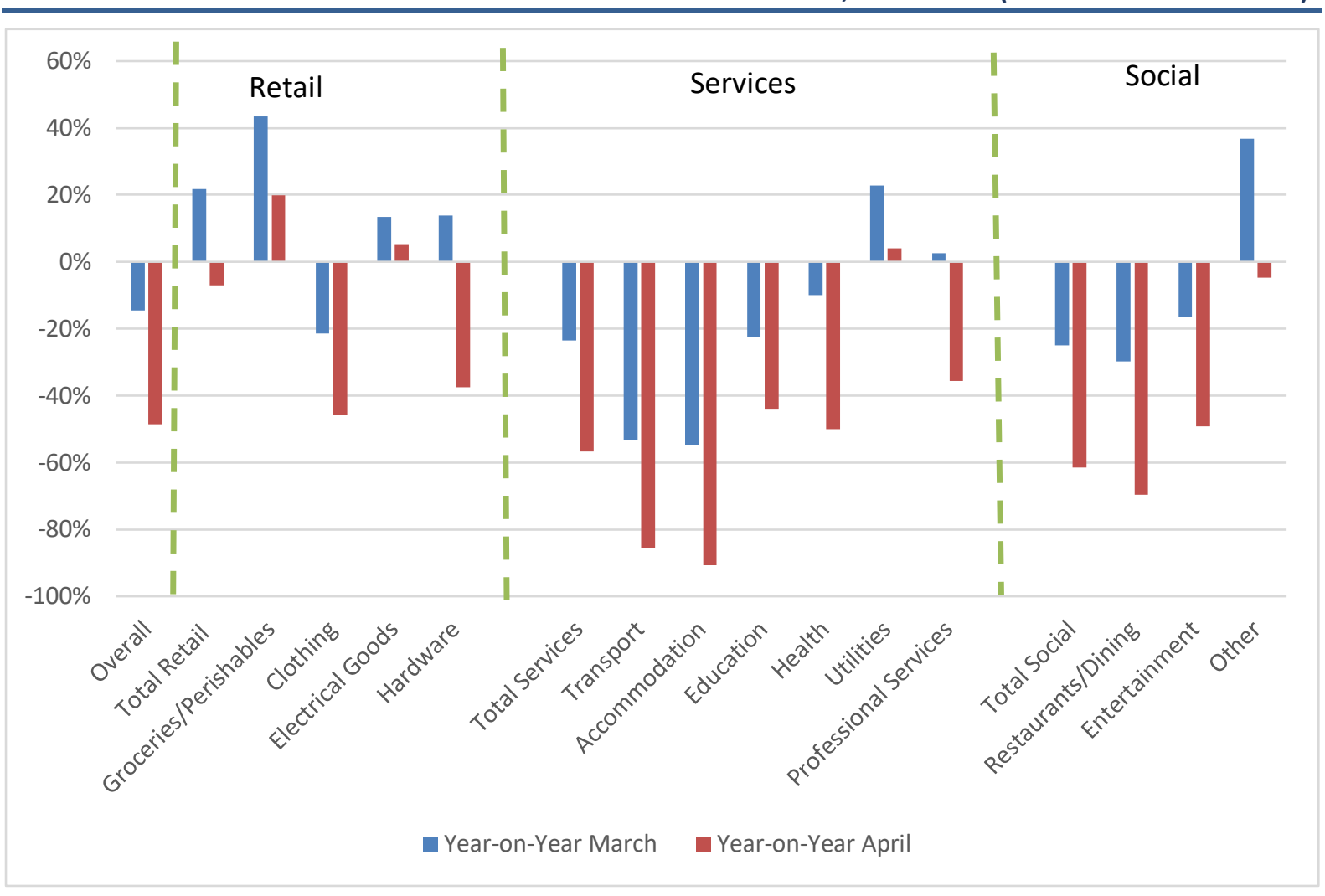

Source: Authors' calculations using Central Bank of Ireland Credit and Debit Card data, Table A.13.

While the above data point towards a major reduction in the volume of activities and level of expenditure on goods and services, there have also been price developments during the pandemic, which may have an impact on the overall level of household consumption. The significant fall in oil prices internationally will result in a reduction in the cost of related goods and motoring expenses. Figure 2.5 presents the trend in the CPI as well as the CSO measure of rental prices on a month-on-month change basis. The figures for April suggest that price inflation, as measured by the CPI and the CPI Rent Index, began to decline as the pandemic

\footnotetext{
${ }^{5}$ These data are available at: https://centralbank.ie/statistics/data-and-analysis/credit-and-bankingstatistics/credit-and-debit-card-statistics.
} 
occurred.

FIGURE 2.5 INFLATION - MONTH-ON-MONTH (\%)

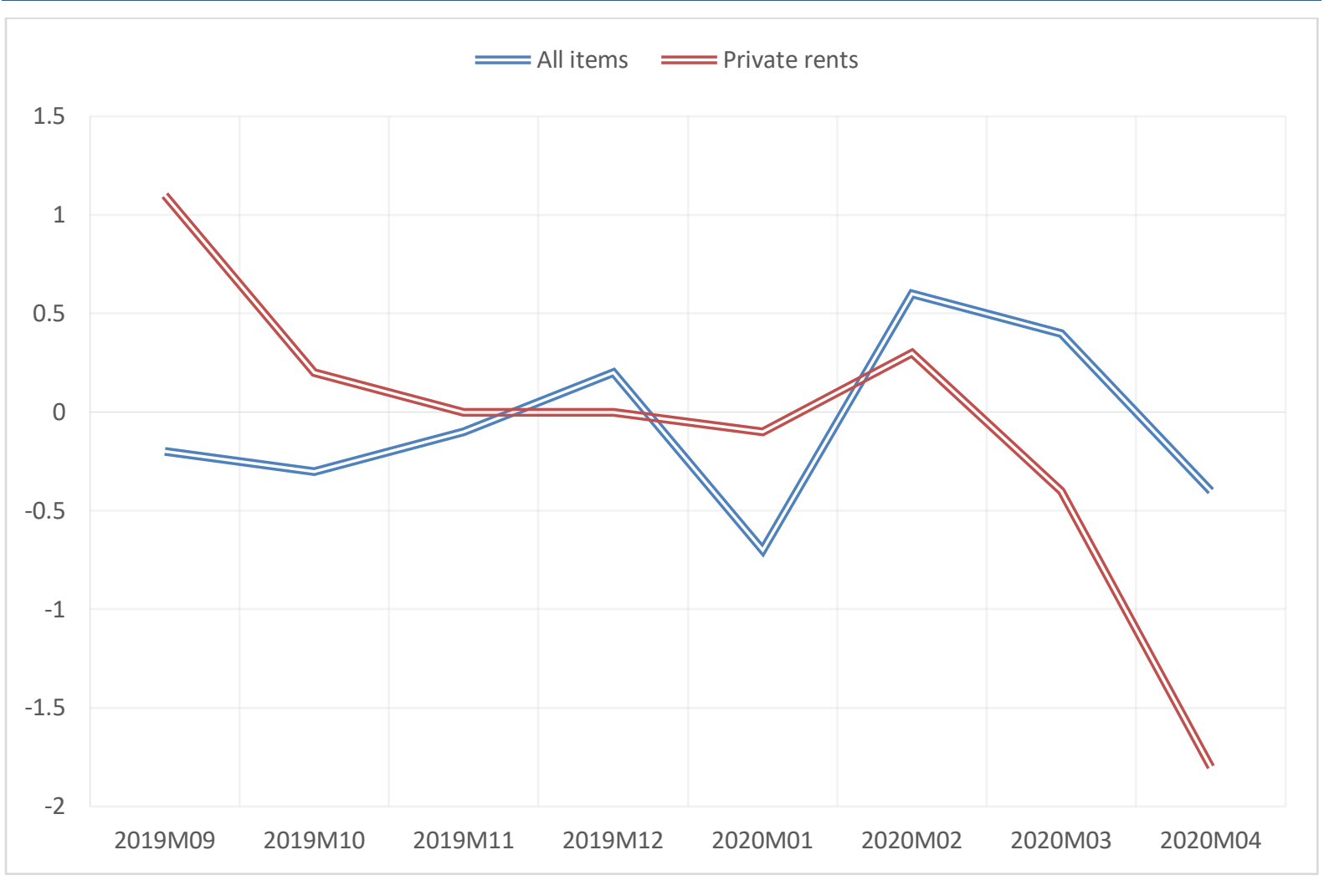

Source: Central Statistics Office.

\section{POLICY RESPONSES TO THE PANDEMIC}

The State's response, primarily aimed at containing the pandemic's spread and mitigating the impact on the economy, has been rapid and wide-ranging. The Government has introduced extraordinary measures to support household incomes. A Pandemic Unemployment Payment (PUP) has been made available to those experiencing unemployment due to the economic contraction. While the payment now has two tiers, originally it was a flat-rate payment of $€ 350$ per week. A Temporary Wage Subsidy Scheme (TWSS) has also been established, which subsidises pandemic-affected employers; the salaries of employees are subsidised in this scheme and are payable at tiered and tapered rates depending on a given employee's prior and current earnings.

The CSO's COVID-19 adjusted monthly unemployment rate (the new, exceptional measure of unemployment) stood at 28.2 per cent for April, falling slightly to 26.1 per cent for May and 22.5 per cent for June. This measure classifies PUP recipients as unemployed, in addition to those on traditional unemployment supports, but does not include TWSS recipients. By 12 May 2020, 589,600 people were in receipt of the PUP. In addition, as of 14 May 2020, 464,400 employees had received at 
least one payment under the TWSS. As of May 2020, approximately $1.14 \mathrm{~m}$ people or 46 per cent of the labour force were on unemployment benefits or other income-related policy supports. ${ }^{6}$

In the rental sector, the Government responded by introducing a range of measures intended to insulate rental markets from the general economic disruption, for a period of at least three months. Evictions, other than in exceptional circumstances, are not permissible. Any rental payment increases that had been underway at the onset of the pandemic were paused, and other rent price increases were proscribed. The Government also signalled that the Department of Employment Affairs and Social Protection would use maximum flexibility of the Rent Supplement scheme to provide necessary supports to tenants; the Rent Supplement scheme (as discussed further in Chapter 3 ) is a shortterm income support intended to assist tenants in the private market who cannot afford their rent (Government of Ireland, 2020).

To date, several studies point to an adverse impact on the rental sector. Byrne et al. (2020) estimated that 44 per cent of households working in the economic sectors most severely affected by the pandemic were renters. For many such households, their market income collapsed and was partially replaced by state income supports or subsidies. The obligation to make rental payments - the principal regular expense for many households - continued, unlike for many mortgaged households for which payment holidays were available. Survey evidence collected at the beginning of the pandemic and published in April 2020 (Central Statistics Office, 2020a) indicates that, at that stage, among the overall population, a relatively low proportion reported financial difficulties. Two per cent of respondents reported rent or mortgage difficulties; 4 per cent of respondents aged 35 to 54 stated that they could not make rent or mortgage payments as a result of the pandemic, compared to 2 per cent among the 24 to 34 and 55 to 64 cohorts.

\footnotetext{
${ }^{6}$ This refers to individuals on the Live Register, PUP or TWSS. Available at: https://statbank.cso.ie/px/pxeirestat/Statire/SelectVarVal/Define.asp?maintable=LRM20\&PLanguage=0
} 


\section{CHAPTER 3}

\section{COVID-19 and Private Rental Affordability}

\section{INTRODUCTION}

The aim of this chapter is threefold. First, we explore housing affordability in the private rental sector just prior to the onset of the COVID-19 pandemic to document the extent to which households faced affordability pressures. Second, we use a scenario-based approach to simulate the potential impact on rental market affordability of the labour-market shocks associated with the COVID-19 economic crisis. Our approach uses a static microsimulation model, which applies a labourmarket shock across households and then re-estimates likely affordability outcomes based on selected scenarios. Finally, we look at factors that may mitigate or offset the labour-market shock. Specifically, we examine whether changes to consumption bundles may have offset any affordability shocks in the short run, as well as looking at savings as a buffer. We also explore what role Rent Supplement could play in offsetting household income shocks.

\section{WHICH HOUSEHOLDS ARE CURRENTLY IN THE RENTAL SECTOR?}

The analysis in this section provides an overview of the rental sector by profiling the households across a number of characteristics such as age, size, household structure, position in the income distribution, employment status and sector of employment.

The focus of this paper is on households renting in the private market that are not in receipt of local authority subsidies (such as the Housing Assistance Payment), do not lease from an Approved Housing Body and do not receive Rent Supplement. In terms of the structure of the rental sector using the SILC weights, our sample accounts for 46.7 per cent of all renters. Private renters receiving state support account for a further 16.9 per cent of renters, while the remaining 36.4 per cent are local authority tenants. This covers approximately 230,000 households. Our analysis is based on the 2018 Survey on Income and Living Conditions (SILC). To represent the affordability picture as close as we can get to the period immediately preceding the COVID-19 pandemic, we uprate rents and incomes to 2019 Q4 values. $^{7}$

To contextualise the type of households analysed in this study, Figure 3.1 presents the share of households in the rental sample we use relative to the overall rental market and mortgage households. While nearly 30 per cent of renters in general (including local authority tenants) come from the bottom quartile of the income

\footnotetext{
${ }^{7}$ We uprate monetary variables to their 201904 levels using a range of indices and growth factors, which are detailed below in the Simulating the Unemployment and Labour Market Shock section of this chapter.
} 
distribution, only 12 per cent of our non-supported private rental sample are households with these income levels. Our sample therefore represents, in the main, higher-income renters. This is unsurprising given that many renting households at the lower end of the income distribution are likely to be in receipt of some degree of state support towards their rental payments. The median gross and net income levels (Table 3.1) in our sample are approximately $€ 57,000$ and $€ 48,000$ respectively, well above incomes for the overall rental sector, but lower than mortgaged households.

\section{FIGURE 3.1 PERCENTAGE OF HOUSEHOLDS BY TENURE AND INCOME DISTRIBUTION}

60

50

40

๙० 30

20

10

0

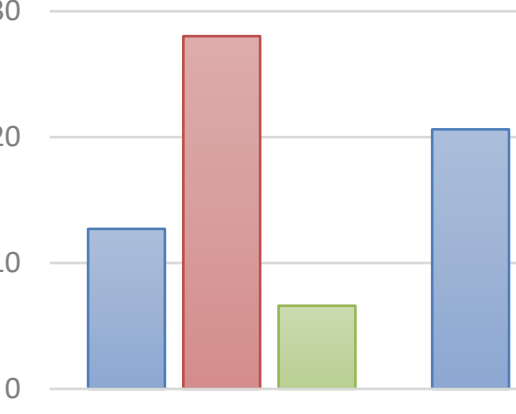

Quartile 1

Quartile 2
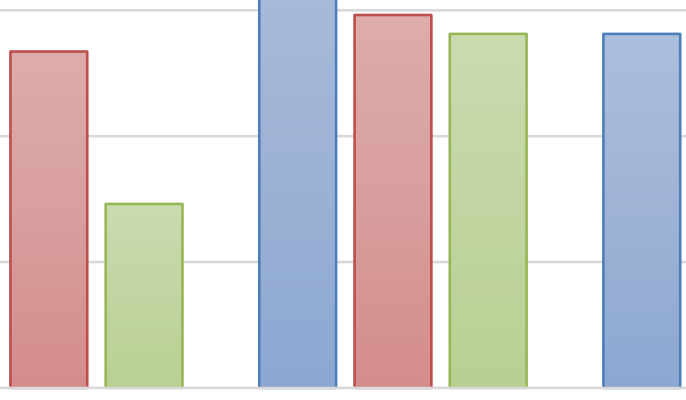

Quartile 3

Quartile 4

INCOME QUARTILE

$\square$ Non-Supported Private Rental

$\square$ Any Rental

$\square$ Mortgaged

Source: Authors' calculations using SILC 2018.

Note: Q1 refers to households in the lowest quartile of the income distribution; Q4 captures households in the highest income quartile. Income quartiles are based on the population income distribution.

Table 3.1 presents further descriptive statistics for our sample of households renting in the private sector not in receipt of housing subsidies. To allow us to see how these households compare to those in other tenures, the final two columns of Table 3.1 include households in any rental accommodation (including those in local authority-rented properties, those in the private sector in receipt of housing subsidies and those paying market-priced rents) and mortgaged households.

Regarding age, the majority of adults living in our sample of non-supported private rental households are young; three-quarters are aged below 40, compared to 60 per cent for the rental sector as a whole and only 40 per cent in mortgaged 
households. In addition, nearly 30 per cent of our private rental sample are aged below 30 . There are fewer single-adult households relative to the rental sector as a whole; just under one-fifth of these households contain only one adult (with or without children). Our private rental sample sees a higher proportion of households with two or more adults relative to other tenures. These likely contain a mix of couples and groups of adults living as housemates. A total of 45 per cent of these non-supported private rental households contain children.

Table 3.1 shows that private rental households have a strong attachment to the labour force, with 85 per cent of adults employed. This figure falls to 60 per cent for households in all types of rental accommodation. Of those in employment, just over 70 per cent are full-time employees while 11 per cent are self-employed similar figures to mortgaged households.

Turning to the sector of employment, we see that 15 per cent of workers living in private rental households are employed in the accommodation and food sectors, more than three times as many as in mortgaged households. In addition, 14 per cent of private rental sector workers are employed in wholesale and retail trade, with a further 13.5 per cent employed in manufacturing. Private rental households are only around half as likely as mortgaged households to be in public sector jobs less likely to be affected by the pandemic, such as those in public administration, education and health. While there are indeed more renters in sectors such as ICT and professional, scientific and technical jobs whose incomes may be relatively insulated by the shock, there is a relatively large share of renters in employment in the accommodation and food sectors. Given that these sectors are particularly affected by COVID-19, a large number of renters will be affected. The strong labour-market attachment, and, in particular, the relatively high proportions of workers in the most at-risk sectors indicate that households in the private rental sector are likely to be disproportionately affected by the shock to the labour market and the resulting impact on household incomes. 


\begin{tabular}{|c|c|c|c|}
\hline & $\begin{array}{r}\text { Non-supported } \\
\text { Private Rental }\end{array}$ & Any Rental** & Mortgaged \\
\hline P(25) Annual Gross Income (€) & 42775 & 24822 & 54154 \\
\hline Median Annual Gross Income (€) & 57410 & 41148 & 82248 \\
\hline$P(75)$ Annual Gross Income (€) & 82353 & 61881 & 113524 \\
\hline$P(25)$ Annual Net Income (€) & 36154 & 23885 & 44747 \\
\hline Median Annual Net Income $(€)$ & 48911 & 38143 & 64127 \\
\hline P(75) Annual Net Income (€) & 67404 & 52902 & 82807 \\
\hline \multicolumn{4}{|l|}{ Household Composition (\% of households) } \\
\hline 1 adult, no kids & 12.6 & 19.0 & 15.0 \\
\hline 1 adult, $1+$ kids & 5.6 & 12.2 & 2.0 \\
\hline $2+$ adults, no kids & 42.0 & 32.3 & 30.9 \\
\hline $2+$ adults, $1+$ kids & 39.8 & 36.5 & 52.1 \\
\hline \multicolumn{4}{|l|}{ Age (\% of adults only) } \\
\hline $18-29$ & 28.6 & 25.1 & 15.6 \\
\hline $30-39$ & 45.8 & 36.3 & 23.4 \\
\hline $40-49$ & 17.6 & 19.5 & 36.7 \\
\hline $50+$ & 8.0 & 19.1 & 24.2 \\
\hline \multicolumn{4}{|l|}{ Employment Status (\% of adults only) } \\
\hline Employed & 85.1 & 60.7 & 80.1 \\
\hline Unemployed & 4.5 & 10.0 & 3.3 \\
\hline Inactive or Retired & 10.4 & 29.3 & 16.6 \\
\hline \multicolumn{4}{|c|}{ Employment Type (\% of employed adults only) } \\
\hline Employee FT & 71.3 & 63.5 & 70.3 \\
\hline Employee PT & 17.6 & 26.8 & 16.1 \\
\hline Self-employed & 11.1 & 9.8 & 13.5 \\
\hline \multicolumn{4}{|c|}{ Employment Sector (\% employed adults only) } \\
\hline Manufacturing & 13.5 & 11.4 & 11.2 \\
\hline Construction & 4.2 & 5.5 & 4.9 \\
\hline Wholesale and retail trade & 14.2 & 15.8 & 12.8 \\
\hline Transportation and storage & $*$ & $*$ & 5.8 \\
\hline Accommodation and food & 14.9 & 13.8 & 4.5 \\
\hline Information and communications & 9.3 & 7.4 & 6.4 \\
\hline Financial, insurance, real estate & $*$ & $*$ & 6.3 \\
\hline Professional, scientific and technical & 8.1 & 6.0 & 7.0 \\
\hline Admin and support services & 4.6 & 5.1 & 3.4 \\
\hline Public administration & $*$ & $*$ & 7.3 \\
\hline Education & 3.7 & 3.2 & 8.3 \\
\hline Health and social work & 10.7 & 13.6 & 14.2 \\
\hline Arts, entertainment, recreation & 5.8 & 7.6 & 5.4 \\
\hline Other & $*$ & $*$ & 2.5 \\
\hline
\end{tabular}

Source: SILC 2018.

Note: $\quad{ }^{* *}$ Any rental contains all households in any type of rental accommodation, i.e. households in the private rental sector (both those in receipt of housing supports, e.g. HAP, and those not) and the local authority rental sector. Figures reported are percentages unless otherwise indicated. *Number of observations too low to report these percentages. Age and employment status statistics refer to all adults in these households. Employment type and sector statistics refer to all employed adults in these households. Please note the methodology for determining economic status is different to the LFS. The LFS uses the ILO classification where a person's economic status is 
determined objectively by CSO based on their answers to a number of questions while in SILC, the Principle Economic Status (PES) is used which is a more subjective measure as it is self-determined.

\section{AN OVERVIEW OF AFFORDABILITY ACROSS PRIVATE RENTAL HOUSEHOLDS}

Understanding the position of non-supported private renters in regard to their housing affordability is critical to determining how they have been affected by the onset of the COVID-19 pandemic. Recent research by Corrigan et al. (2019) highlighted the long-term structural affordability challenges faced by certain groups in the Irish housing market, particularly those in the private rental market. Our analysis in this paper will draw on the indicators proposed in Corrigan et al. (2019) to give an insight into their affordability position at the onset of the pandemic.

In this analysis, we use two different indicators to measure housing affordability, which are presented in Table 3.2. First, we use a simple measure which takes the ratio of rental payment to net income of the household and explores whether this ratio is greater than 30 per cent. This is a commonly used indicator in the international literature (Quigley and Raphael, 2004). ${ }^{8}$ Second, we use a residual income sufficiency ratio (ISR). This metric takes the income left after the rental payment is made and determines whether it is sufficient to cover a minimum required level of expenditure. We use the Vincentian Partnership Minimum Essential Standing of Living (MESL) expenditure levels. ${ }^{9}$ Values of this ratio less than one indicate that the household does not have enough income to cover basic requirements and hence are an indicator of housing affordability stress.

\footnotetext{
${ }^{8}$ As discussed in footnote 4.

${ }^{9}$ Our use of MESL is motivated by a number of factors. First, the use of minimum acceptable expenditure floors is well established in the literature on housing affordability when attempting to benchmark households under strain (see Corrigan et al., 2019 and Gerardi et al., 2017). Indeed, Corrigan et al. (2019) put it forward as a good measure to capture affordability as it abstracts from households' own choices. Second, it is appropriate for what we are attempting to measure. Affordability is a very vague concept and sufficient residual income levels can vary greatly at an idiosyncratic level for households (i.e they depend on their preferences and requirements, and their regular expenditure basket). Therefore, a commonly accepted level of required expenditure is needed to compare across households in a common manner. Few such baskets exist as measures. The MESL is one measure for Ireland that is broadly known and can be used consistently over time.
} 


\begin{tabular}{|l|l|l|}
\hline Indicator & Name & Detail \\
\hline Indicator 1 & $\begin{array}{l}\text { \% of households with } \\
\text { rent to net income ratio } \\
>30 \text { per cent }\end{array}$ & $\begin{array}{l}\text { Measure explores how much of net take-home } \\
\text { income is spent on rental payments. }\end{array}$ \\
\hline Indicator 2 & $\begin{array}{l}\text { \% of households with } \\
\text { sufficient residual } \\
\text { income ratio }<1\end{array}$ & $\begin{array}{l}\text { Indicator measures whether households have } \\
\text { sufficient residual income after housing cost to cover } \\
\text { a minimum level of required expenditure. }\end{array}$
\end{tabular}

An overview of the pre-COVID-19 affordability position of our non-supported private rental sample is presented in Table 3.3. The median gross and net monthly incomes for the sample of households included in our analysis are approximately $€ 4,800$ and $€ 4,100$ respectively. ${ }^{10}$ The median rent-to-income ratio is approximately 23 per cent. Using indicator 1 , the per cent of households with a rent-to-net income ratio (RTI) greater than 30 per cent is 25 per cent. Taking account of the rental payment, the median level of income left after households have made their monthly payment is $€ 3,224$. Comparing these figures to the appropriate required minimum essential level of expenditure ${ }^{11}$ we find that, at the median, residual household income is 40 per cent higher than the minimum level after rental payment; i.e. the median ratio is 1.4 . Just over 30 per cent of households have insufficient income to meet the minimum standard of living expenditure level. This highlights the scale of households in this category that are vulnerable to housing affordability pressures. Using the weights from the survey, this would provide an estimated number of households of approximately 70,000.

\footnotetext{
${ }^{10}$ The $25^{\text {th }}$ percentile gross and net monthly income figures are $€ 3,565$ and $€ 3,013$ respectively. The $75^{\text {th }}$ percentile gross and net monthly income figures are $€ 6,863$ and $€ 5,617$ respectively.

${ }^{11}$ We have assessed the minimum level of required expenditure by mapping minimum expenditures for six different household types (separately for urban and rural households) from the Vincentian Partnership's MESL database to the SILC data.
} 


\begin{tabular}{|l|c|}
\hline \multicolumn{1}{|c|}{} & Private Rental - no Housing Supports \\
\hline Gross Income (monthly) & 5782 \\
\hline Mean & 4784 \\
\hline Ned Income (monthly) & \\
\hline Mean & 4503 \\
\hline Median & 4076 \\
\hline Rent to Income (RTI) & \\
\hline Mean & 25.8 \\
\hline Median & 23.6 \\
\hline \% with RTI>30\% & 25.7 \\
\hline Residual Income (monthly) & \\
\hline Mean & 3461 \\
\hline Median & 3224 \\
\hline Income Sufficiency Ratio (ISR) & \\
\hline Mean & 1.8 \\
\hline Median & 1.4 \\
\hline
\end{tabular}

Source: SILC 2018.

\section{SIMULATING THE UNEMPLOYMENT AND LABOUR-MARKET SHOCK}

As outlined in Chapter 2, the labour-market shock resulting from the pandemic has been immediate and extreme. The CSO's COVID-19 adjusted monthly unemployment rate stood at 28.2 per cent for April, falling slightly to 26.1 per cent for May. ${ }^{12}$ By 12 May 2020, 589,600 people were in receipt of the PUP. In addition, as of 14 May 2020, 464,400 employees had received at least one payment under the TWSS. ${ }^{13}$

\footnotetext{
${ }^{12}$ The COVID-19 adjusted figure includes those classed as unemployed in the traditional sense as well as those in receipt of the PUP. Since the analysis was completed, the COVID-19 adjusted monthly unemployment rate for June of 22.5 per cent has been published.

${ }^{13}$ PUP numbers are published by the Department for Employment Affairs and Social Protection (DEASP, 2020) and refer to the number of individuals claiming PUP on 12 May 2020. TWSS numbers are published by the Office of the Revenue Commissioners and refer to the number of workers who have received at least one TWSS payment as of 14 May (Revenue Commissioners, 2020). We use the number of workers who have received at least one TWSS payment (adjusted for outflows) rather than the number of individuals in receipt of a TWSS payment in a given week as the latter is not equivalent to the overall number of people supported by the scheme due to the differing periodicity in the payment of wages and salaries (weekly, monthly, etc). Not everyone supported by the scheme will appear in each week; they will only appear in the week their payment is processed. On 9 June 2020, the CSO released a sectoral breakdown of the number of individuals in receipt of the PUP as well as a sectoral breakdown of the number that received a TWSS payment in a given week and the number who have received at least one TWSS payment (CSO 2020b). Our analysis was carried out prior to this
} 
Figure 3.2 shows that job losses and employees being moved onto TWSS have not been evenly distributed across sectors. It shows the proportion of workers on (i) PUP, (ii) TWSS and (iii) remaining in normal employment (unsubsidised workers) by employment sector for the entire labour force. ${ }^{14}$ There is significant variation across sectors, with more than 70 per cent of workers in the food and accommodation sector now on PUP and only 5 per cent still employed. Less than 20 per cent of construction workers remained in employment by mid-May. In contrast, more than 85 per cent of workers in information and communications and public sector jobs such as public administration, education and healthcare remained in employment.

\section{FIGURE 3.2 PROPORTION OF WORKERS ON PUP, TWSS AND REMAINING IN WORK BY SECTOR}

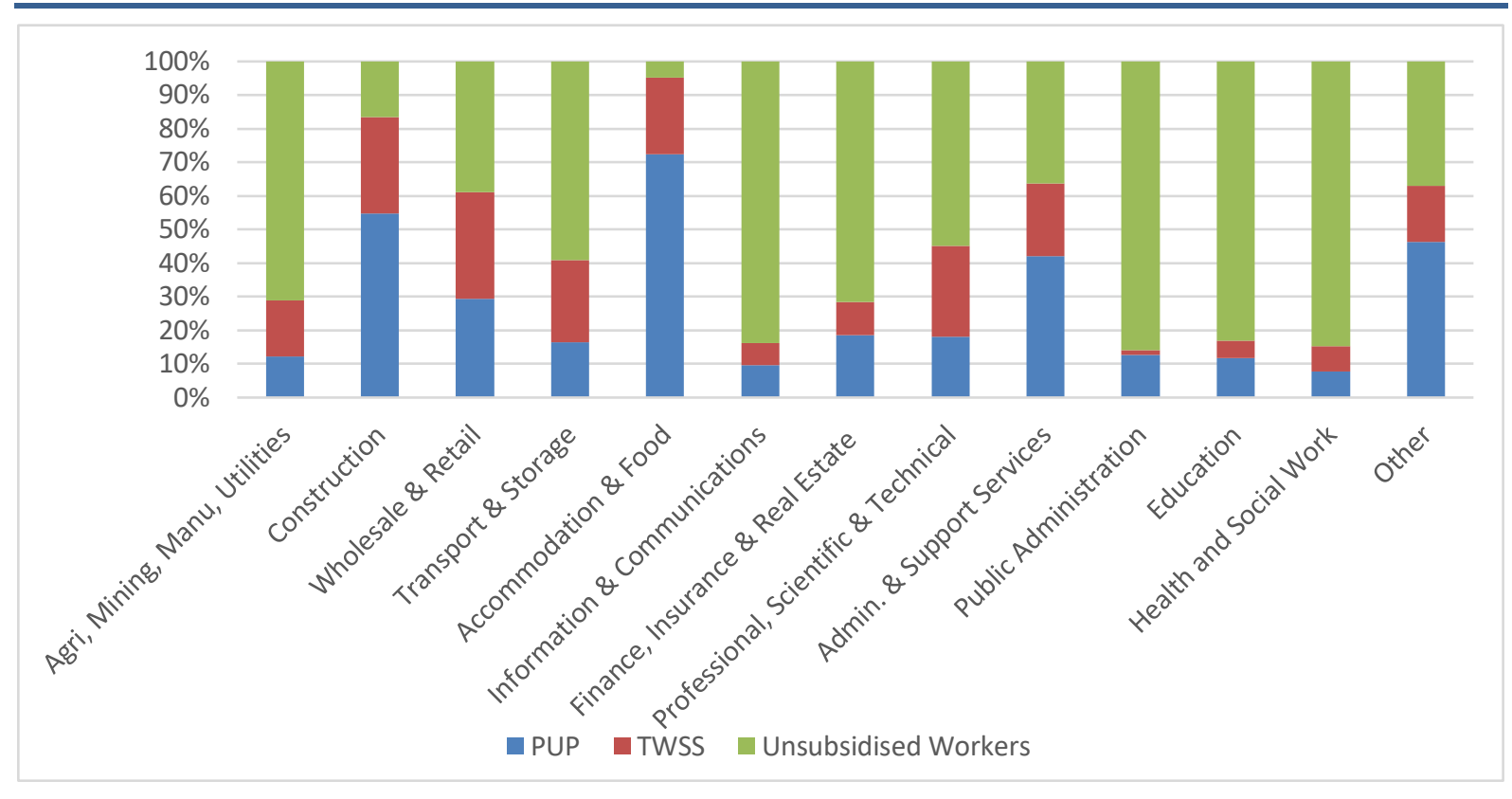

Sources: Authors' own calculations based on TWSS data provided by the Office of the Revenue Commissioners (Revenue Commissioners, 2020), PUP data provided by the Department for Employment Affairs and Social Protection (DEASP, 2020) and estimates of the total persons employed in each sector from the 2019Q4 Labour Force Survey.

Note: $\quad$ PUP numbers as of 12 May 2020 and TWSS numbers as of 14 May 2020.

To simulate the impact of the pandemic labour-market shock on incomes and the resulting housing affordability indicators, we use a static microsimulation model; that is, it provides an assessment at one particular point in time. This analysis is based on the 2018 Survey on Income and Living Conditions (SILC). SILC is a nationally representative household survey containing detailed information on households' incomes, employment conditions and housing costs. These data are uprated to 2019 Q4 values, to be as representative as possible of the period

release. Most recent figures suggest that 410k employees were currently on the TWSS as of 2 July 2020 and 414k people were in receipt of the PUP on 6 July 2020.

${ }^{14}$ Please note that differences exist in the sectoral data between CSO and the Department of Employment and Social Protection for the pandemic unemployment payment and between CSO and the Revenue Commissioners for sectoral data on TWSS payments. 
immediately preceding the COVID-19 pandemic. ${ }^{15}$ Broadly, our model simulates the actual extent of the unemployment shock as far as our nationally representative sample of households is concerned. Therefore, the scale of the unemployment shock at the aggregate level is replicated for the sample of households in the SILC data. We then adjust incomes according to the supports they receive and recalculate the relevant indicators of housing affordability. The model is part of a microsimulation tool for calculating housing affordability and tenure choice that the ESRI is developing.

A number of important assumptions are made in this analysis. First, this is a shortterm analysis of the immediate impacts of the pandemic and therefore assumes no behavioural changes. Second, in this analysis we only consider workers who move onto either PUP or the TWSS; ${ }^{16}$ we do not consider the impact of any changes in hours or earnings of those not part of either scheme. We also assume no changes to non-employment incomes. Third, we treat PUP and TWSS payments as net income payments in this short-term, three-month time frame analysis. While these payments will be taxable, any tax liability will be determined at the year end and will depend on the individual's earnings over the entire tax year. Our analysis is therefore done on a cashflow basis, which we feel is appropriate when taking such a short-term analytical horizon. We model the PUP as a flat-rate payment of $€ 350$ as per the original calibration of the scheme which was in operation for the duration of our three-month timeframe of analysis.

In the first stage of the modelling, all individuals in employment are randomly allocated to either (i) PUP, (ii) to TWSS or (iii) to remaining in normal employment based on the proportions of workers on these schemes in their sector of employment. ${ }^{17}$ The allocation into these schemes within sectors is done following

\footnotetext{
${ }^{15}$ We uprate monetary variables to their 2019 Q4 levels using a range of indices and growth factors. Employment incomes are grown forward by CSO growth rates in hourly earnings by sector. Family allowances are grown forward by the growth rate in child benefit, and all other benefits are grown forward by the growth rate in the personal rate for non-means-tested benefits. Interest and investment incomes are grown forward by CPI. These uprating factors are applied to gross incomes, and the original ratios between gross and net income, separately for employment and non-employment income, are then used to obtain uprated total net incomes. We separate the components of income into employment and non-employment incomes as we will require the net employment income component when applying PUP and TWSS income shocks. This assumes the uprating does not cause any change in the tax and benefit situation of the household. It also assumes no structural change in the tax-benefit system apart from PUP and TWSS between 2018 and 2020. Rents are grown forward using the NUTS3 regional median values from a property-matched sample of Residential Tenancies Board (RTB) data used in Ahrens et al. (2019a;b). See Appendix 2 for further details.

${ }^{16}$ There are circumstances where households would be better off on the Jobseeker's Benefit rather than the PUP, such as single-adult households with one or more dependent children. We apply the PUP to all households; thus we do not apply a modelling strategy of the optimal benefit policy for each individual household. This is likely to bias downwards the transfer income that such households would receive in our simulation.

17 In our microsimulation, we subtract the number of people that have left the TWSS from the number of employees that have received at least one TWSS payment as per the figures released by the Revenue Commissioners (2020) for 14 May 2020. We keep the proportions of TWSS recipients across sectors the same as in Revenue Commissioners (2020).
} 
statistical randomisation procedures; we did not have data on whether particular groups of workers within the same sector are more likely than others to be supported by the TWSS or the PUP. ${ }^{18}$ Any individuals who were not employed at the outset remain so, and their employment status does not change at any point in the simulation. The simulation focuses on changing the employment status of those who were working in advance of the COVID-19 labour-market shock. It must be noted that this labour-market simulation is conducted on the entire sample of workers in SILC, rather than specifically on our sample of non-supported private renters, as the numbers on PUP and TWSS refer to the population as a whole. This means that any resulting differences in the proportions of workers on PUP, TWSS and remaining in work between the entire labour force and our specific sample of non-supported private renters are driven by differences in the sectors of employment between these two groups.

In the second stage of the modelling, having assigned each worker a new employment status, we adjust each worker's income accordingly. We model two income scenarios: (i) a pandemic support scenario with PUP and TWSS payments as happened in practice, and (ii) an alternative, traditional payments scenario which instead sees those on the PUP receive the Jobseeker's Benefit payment rate instead of the enhanced PUP support. Those on TWSS in this second scenario see their payments remain identical to those in scenario one. As TWSS recipients are still employed, we do not have a good counterfactual to ascertain how many would be made unemployed in the absence of the subsidy. We therefore treat these employees as employed in both scenarios.

In the first scenario, individuals on the PUP receive $€ 350$ per week. TWSS recipients previously earning less than $€ 412$ per week receive 85 per cent of their pre-COVID19 earnings. Those previously earning $€ 412-500$ receive a flat rate of $€ 350$ per week, while those previously on $€ 500-586$ per week receive 70 per cent of their pre-COVID-19 earnings. We assign individuals who previously earned more than $€ 586$ per week a flat €350 per week payment. In practice, the level of TWSS payment for those whose prior earnings were greater than $€ 586$ per week depends on the level of top-up they receive from their employer. As we do not have any data on the level of top-ups employees in different sectors may be receiving, we simply allocate these workers a flat rate of $€ 350$ per week. ${ }^{19}$ It is likely that many of these previously higher-income workers are actually receiving more than this in

\footnotetext{
${ }^{18}$ We are therefore not able to model any within-sector differences in the likelihood of an individual receiving PUP or TWSS payments.

${ }^{19}$ According to the TWSS scheme parameters, those previously earning more than $€ 960$ per week are not eligible for the scheme. Due to the lack of information on employer top-ups and the very small number of households in our non-supported rental sample who previously earned more than $€ 960$ per week, we simply allocate these individuals a TWSS payment of $€ 350$.
} 
total as a result of employer top-ups. ${ }^{20}$ Our scenario can therefore be thought of as the most extreme scenario these TWSS recipients would face.

In the second, alternative scenario, individuals allocated to the PUP instead receive the appropriate level of Jobseeker's Benefit. ${ }^{21}$ This scenario represents what would have happened had traditional unemployment supports remained in place, rather than the enhanced replacement income levels of the PUP. As SILC does not contain information on whether an individual has made sufficient PRSI contributions to qualify, we therefore determine the appropriate Jobseeker's Benefit rate based on each worker's pre-COVID-19 weekly employment income. In addition, those with dependent children receive additional child allowances depending on the income of any other adults in the household. ${ }^{22}$ Individuals on TWSS see their payments remain unchanged from the first scenario.

Turning to the results of our labour-market microsimulation exercise, Figure 3.3 presents the proportions of workers on (i) PUP, (ii) TWSS and (iii) remaining in work. For our sample of workers living in non-supported private rental households, 27.5 per cent are in receipt of PUP, and a further 15 per cent on TWSS. The proportion of workers on the PUP is four percentage points higher relative to the estimates of the entire workforce. This is unsurprising given the higher proportion of workers in sectors such as accommodation and food, for instance.

\footnotetext{
${ }^{20}$ The proportion of TWSS recipients receiving some degree of top-up ranged from 58 per cent in the week to 30 March to 88 per cent in the week to 16 June 2020. www.revenue.ie/en/corporate/information-aboutrevenue/statistics/number-of-taxpayers-and-returns/covid-19-wage-subsidy-scheme-statistics.aspx

${ }^{21}$ We do not distinguish between Jobseeker's Benefit and Jobseeker's Allowance. Some individuals would not have been eligible for Jobseeker's Benefit but would have received Jobseeker's Allowance. As a simplifying assumption we apply Jobseeker's Benefit to all.

${ }^{22}$ We use Jobseeker's Benefit weekly rates 2020, available at www.citizensinformation.ie/en/social_welfare/social_welfare_payments/unemployed_people/jobseekers_be nefit.html
} 


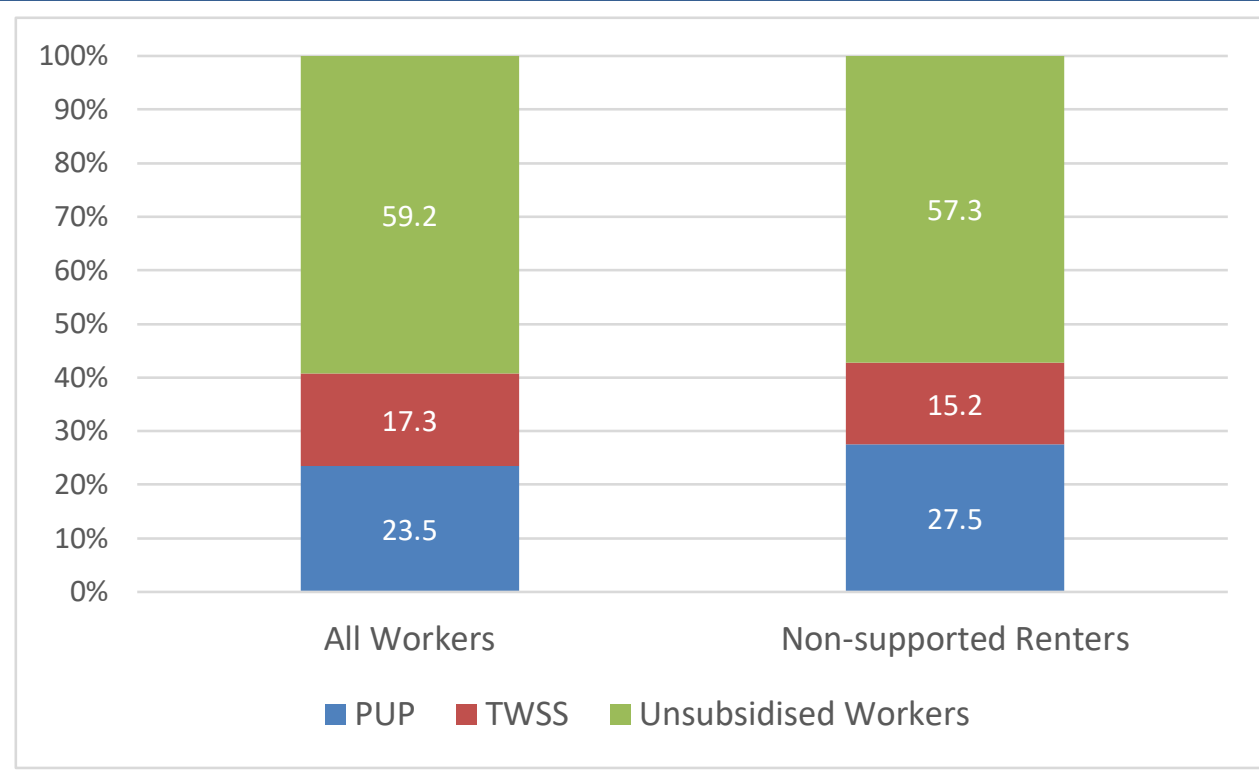

Sources: Authors' calculations using SILC 2018.

An important point to consider here is the age distribution of affected workers. Roantree $(2020)^{23}$ illustrates that younger people have been disproportionately affected by job losses resulting from the COVID-19 pandemic. This is particularly relevant for our analysis; we showed in Table 3.1 that the adults living in our sample of non-supported private rental households are typically younger in comparison with those in other tenures. As we do not have data on the sectoral breakdowns of PUP and TWSS recipients by age group, our random allocation of workers within sectors does not consider worker age. We are therefore implicitly making the assumption that differences across age groups are driven entirely by differences in the sectors of employment between these groups. In Table 3.4 we show that the age distribution in our simulation is broadly consistent with the actual age distribution of PUP claimants published by DEASP (2020). However, the proportion of those allocated to the PUP in our simulation who are aged less than 25 (over 55) is slightly lower (higher) when compared to the actual age distribution of PUP claimants.

TABLE 3.4 AGE DISTRIBUTION OF PUP RECIPIENTS

\begin{tabular}{|c|c|c|}
\hline 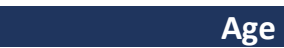 & DEASP Figures (\%) & Microsimulation (\%) \\
\hline$<25$ & 20.5 & 14.3 \\
\hline $25-34$ & 22.9 & 23.5 \\
\hline $35-44$ & 23.9 & 21.2 \\
\hline $45-54$ & 18.9 & 22.6 \\
\hline $55+$ & 13.7 & 18.3 \\
\hline
\end{tabular}




\section{THE IMPACT ON AFFORDABILITY}

The resulting household income shocks from the pandemic labour-market shock are presented in Table 3.5. On average, non-supported rental households have seen their net incomes decrease by 8.8 per cent as a result of the pandemic. Just under half of non-supported private rental households have seen a fall in their income, while a third see no change and 18 per cent actually see a rise in income. If the PUP had not been in place and individuals who lost their jobs had instead received Jobseeker's Benefit, a larger 60 per cent of these non-supported rental households would have seen a fall in income, and the mean percentage change in income would have been almost double, at 16.5 per cent. The final two columns of Table 3.5 present the income shocks for the entire population, for comparison. It is clear that non-supported rental households have seen larger income shocks relative to the population as a whole. This is unsurprising as we have previously documented that, prior to the pandemic, these rental households were younger, more likely to be employed and also more likely to be working in certain sectors which have been hit hardest by the pandemic such as the accommodation and food sector.

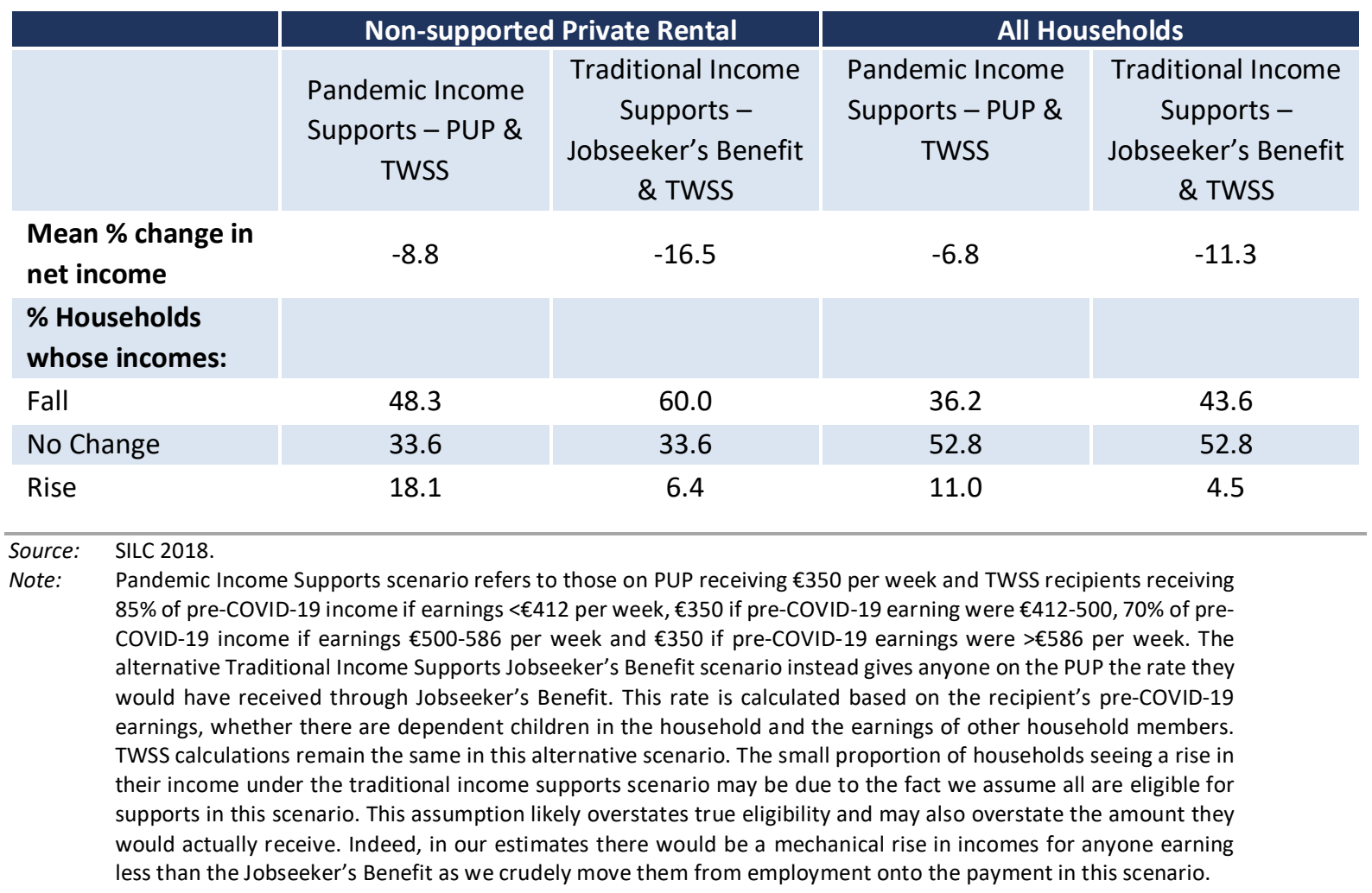

Table 3.6 presents the changes in housing affordability measures arising from the pandemic. The proportion of households paying more than 30 per cent of net income on their rental payments increased from one quarter pre-COVID-19 to one 
third as a result of the economic calibration of the factors arising from the pandemic. The final column of Table 3.6 indicates this would have risen further to 45 per cent had households received Jobseeker's Benefit instead of PUP. We also see that the median residual income left after paying rent fell by $€ 460$; this would have fallen by $€ 810$ under the Jobseeker's Benefit scenario. The proportion of households with an income sufficiency ratio less than 1 rose by 11 percentage points to 41 per cent. It is important to note that the figures presented in Table 3.6 do not take into account any reductions in household consumption that may have occurred during the pandemic. This is an important consideration that we will address in the next section. 
TABLE 3.6 COVID-19 AFFORDABILITY SHOCKS

\begin{tabular}{|c|c|c|c|}
\hline & Baseline - pre-COVID-19 & $\begin{array}{c}\text { Pandemic Income } \\
\text { Supports - PUP \& TWSS }\end{array}$ & $\begin{array}{c}\text { Traditional Income } \\
\text { Supports - Jobseeker's } \\
\text { Benefit }\end{array}$ \\
\hline Mean RTI & 25.8 & 30.1 & 34.4 \\
\hline Median RTI & 23.6 & 25.9 & 27.8 \\
\hline$\%$ with RTI>30\% & 25.7 & 32.3 & 44.4 \\
\hline $\begin{array}{l}\text { Mean Residual income } \\
\text { (monthly) }\end{array}$ & 3461 & 2958 & 2652 \\
\hline $\begin{array}{l}\text { Median Residual } \\
\text { income (monthly) }\end{array}$ & 3224 & 2765 & 2414 \\
\hline Mean ISR & 1.78 & 1.51 & 1.35 \\
\hline Median ISR & 1.44 & 1.23 & 1.08 \\
\hline \% with ISR<1 & 30.1 & 41.0 & 45.4 \\
\hline
\end{tabular}

Source: Authors' calculations using SILC 2018.

\section{ABSORPTION BUFFERS AND POLICY RESPONSES}

In this section, we explore a number of potential factors that may help households to absorb, or that may offset, the shock to incomes caused by the COVID-19 pandemic. In particular, we look at a) the likely changes to consumption patterns during the pandemic that are specific to the public health restrictions on economic and social life needed to suppress the virus, $b$ ) the savings that renters may have accumulated as a financial buffer, and c) the availability of Rent Supplement.

\section{Pandemic-related changes to consumption bundles in the short run}

In Chapter 2, we documented the major reductions to household expenditure that have occurred through households' discretionary choices, and the restrictions on economic and social life which have limited the basket of goods and services available for households to purchase. Coffey et al. (2020) document the major changes to household expenditure across the full range of items that households purchase. While these reductions in expenditure are temporary in nature, they may provide some offsetting reduction in expenditure levels, which may allow households to absorb some, or all, of the income shocks during the initial lockdown phase of the pandemic.

To explore whether this is the case for non-supported private renters, we undertake an exercise which is similar to Coffey et al. (2020), and map changes to expenditure as evidenced by the CSO retail sales data and the Central Bank of Ireland credit and debit-card data to the minimum essential standard of living (MESL) expenditure data. Our aim is to explore the extent to which these pandemic-specific consumption changes may have mitigated the housing affordability pressures of households by reducing their outgoings and creating space to absorb income shocks and continue making rental payments. It must be 
noted that the MESL represents 'the cost of what is needed to enable a life with dignity, at a minimum acceptable standard that members of the public agree nobody should be expected to live below' (Mac Mahon et al., 2019), not a representative consumption bundle for each type of household. The MESL is therefore only one way of measuring minimum expenditure with other combinations also possible. ${ }^{24}$ It cannot therefore be expected that households would keep expenditure at the reduced levels for anything other than the severe public health crisis phase of the pandemic. ${ }^{25}$ This is due to the fact that the reductions in spending due to the public health restrictions (as outlined by Coffey et al., 2020) push consumption below what is needed for normal societal function (such as childcare, transport etc) and these will immediately return as the economic and society reopens.

The main items in the MESL data are presented in Table 3.7. Our approach is to create a pandemic-related consumption basket for the period mid-March to midJune 2020 when the major public health restrictions were in place. Following Coffey et al. (2020), we parameterise the consumption reduction for March and April using a combination of published CSO retail sales data and Central Bank of Ireland credit and debit-card data. A rebound in spending in May and June has been evident from daily Central Bank credit-card data, and we have used these data to increase the expenditure in each category for these months. ${ }^{26}$ Thus we develop a three-month expenditure parameter for each item in the MESL. These are presented in Table 3.7. For the period in question, we also assume that parents do not face childcare costs as per the Childcare Specific Wage Subsidy Agreement announced by the Department of Children and Youth Affairs.

\footnotetext{
${ }^{24}$ It is beyond the scope of this paper to explore this issue.

${ }^{25}$ We do not wish to suggest that the minimum acceptable standard of living has fallen. However, adjusting the reference expenditure downwards, in line with what has happened during the severe public health phase of the pandemic, provides us with a way to explore how affordability pressures have changed over the period, using a common comparison across households.

${ }^{26}$ More detail is available on request from the authors. Daily credit and debit-card data (as well as ATM withdrawals) showed an increase in expenditure of 20 per cent in May relative to April in value terms. A further increase of 17 per cent is evident comparing the first 16 days in June to the first 16 days in May. We have used these adjustments to increase the MESL levels back from their April lows, holding the distribution of the shocks constant across spending categories. While May Retail Sales data are now available from the CSO, these data were not available at the time of analysis.
} 


\begin{tabular}{|c|c|c|c|c|}
\hline & $\begin{array}{l}\text { Data } \\
\text { Source }\end{array}$ & Mapping Group & $\begin{array}{c}\text { Change } \\
(\%)\end{array}$ & $\begin{array}{l}\text { Spending } \\
\text { Factor }\end{array}$ \\
\hline Food & CSO & Retail sale of food $(4711,4721$ to 4729$)$ & 16 & 1.16 \\
\hline Clothing & CSO & $\begin{array}{l}\text { Retail sale of textiles, clothing and } \\
\text { footwear }(4751,4771,4772)\end{array}$ & -77 & 0.23 \\
\hline Personal Care & $\mathrm{CSO}$ & $\begin{array}{l}\text { Retail sale of pharmaceutical, medical and } \\
\text { cosmetic articles ( } 4773 \text { to } 4775 \text { ) }\end{array}$ & 0 & 1.00 \\
\hline Health & $\mathrm{CBI}$ & 2.2.4 Health & -36 & 0.64 \\
\hline Household Goods & $\mathrm{CSO}$ & $\begin{array}{l}\text { Retail sale of household equipment ( } 4741 \\
\text { to } 4743,4752,4754,4759)\end{array}$ & -37 & 0.63 \\
\hline Household Services & $\mathrm{CBI}$ & 2.2. Total Services & -50 & 0.50 \\
\hline Communications & $\mathrm{CBI}$ & 2.4 Other & -2 & 0.98 \\
\hline $\begin{array}{l}\text { Social Inclusion } \\
\text { and Participation }\end{array}$ & $\mathrm{CBI}$ & 2.3.2 Entertainment & -30 & 0.70 \\
\hline Education & $\mathrm{CBI}$ & 2.2.3 Education & -64 & 0.36 \\
\hline Transport & $\mathrm{CBI}$ & 2.2.1 Transport & -79 & 0.21 \\
\hline Household Energy & No change & & 0 & 1.00 \\
\hline $\begin{array}{l}\text { Personal Care } \\
\text { Costs }\end{array}$ & CSO & $\begin{array}{l}\text { Retail sale of pharmaceutical, medical and } \\
\text { cosmetic articles ( } 4773 \text { to } 4775 \text { ) }\end{array}$ & 0 & 1.00 \\
\hline Insurance & No change & & 0 & 1.00 \\
\hline $\begin{array}{l}\text { Savings and } \\
\text { Contingencies }\end{array}$ & No change & & 0 & 1.00 \\
\hline Childcare PT & Closed & & -100 & 1 \\
\hline Childcare FT & Closed & & -100 & 1 \\
\hline
\end{tabular}

Source: Authors' calculations using CSO Retail Sales data and Central Bank of Ireland Credit and Debit-Card data.

Applying these changes to the MESL for different household groups used in our analysis, it can be seen that a considerable reduction, of between 9 and 54 per cent, is identified in the expenditure baskets for the pandemic lockdown period (Table 3.8). The decrease is greatest for households who have children and faced large childcare costs prior to the pandemic. The decline for these groups, if we instead maintained their expenditure on childcare at the pre-pandemic level, would have been between 16 and 24 per cent depending on the housing type and whether they are in rural or urban areas. The reduction in expenditure is larger in rural areas due to the declines in expenditure on transport (cost of motor cars) that is seen in the data. 


\begin{tabular}{|l|l|l|}
\hline \multicolumn{1}{|c|}{ Household Type } & $\%$ Change & $\begin{array}{c}\text { \% Change (keeping childcare at pre- } \\
\text { pandemic level) }\end{array}$ \\
\hline Urban & & $-20 \%$ \\
\hline $2+$ adults with kids (TP2b - school age) & $-27 \%$ & $-18 \%$ \\
\hline 1 adult with kids (OP2b - school age) & $-28 \%$ & $-18 \%$ \\
\hline $2+$ adults with kids (TP2a - younger) & $-50 \%$ & $-16 \%$ \\
\hline 1 adult with kids (OP2a - younger) & $-54 \%$ & $-11 \%$ \\
\hline Pensioner couple & $-11 \%$ & $-9 \%$ \\
\hline Single pensioner & $-9 \%$ & $-19 \%$ \\
\hline Single adult & $-19 \%$ & $-22 \%$ \\
\hline $2+$ adults & $-22 \%$ & $-24 \%$ \\
\hline Rural & $-30 \%$ & $-21 \%$ \\
\hline $2+$ adults with kids & $-29 \%$ & $-24 \%$ \\
\hline 1 adult with kids & $-47 \%$ & $-21 \%$ \\
\hline $2+$ adults with kids (TP2a - younger) & $-50 \%$ & $-20 \%$ \\
\hline 1 adult with kids (OP2a - younger) & $-20 \%$ & $-21 \%$ \\
\hline Pensioner couple & $-21 \%$ & $-24 \%$ \\
\hline Single pensioner & $-24 \%$ & $-16 \%$ \\
\hline Single adult & $-16 \%$ & $-20 \%$ \\
\hline $2+$ adults & $-27 \%$ & \\
\hline
\end{tabular}

Source: Authors' calculations using Vincentian Partnership MESL data.

Note: Household types correspond to categories used by the Vincentian Partnership to measure minimum essential standard-of-living expenditures.

Armed with these estimates, we can recalculate the income sufficiency ratios to take account of the lower level of expenditure and reassess the short-term impacts on affordability. These adjusted affordability measures are presented in the final column of Table 3.9.

TABLE 3.9 IMPACT OF EXPENDITURE REDUCTIONS ON INCOME SUFFICIENCY RATIO AFFORDABILITY MEASURE
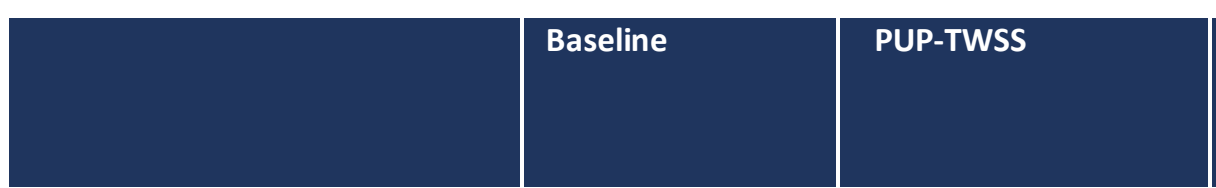

PUP-TWSS
with
adjusted
MESL

\section{Mean ISR}

Median ISR

1.78

1.51

2.10

$\%$ with ISR $<1$

1.44

1.23

1.78

30.1

41.0

18.75

Source: Authors' calculations using SILC 2018.

These estimates indicate that the share of households with an income sufficiency ratio less than one is actually lower than prior to the pandemic. This is due to expenditure adjustments outweighing falls in incomes. This points to much of the 
increased affordability pressure which arises from labour-market developments being offset by changes to consumption in the very short term. A large majority of this adjustment is coming from households whose childcare costs are no longer required, with such activities closed due to public health concerns.

It must be noted that these changes, while potentially providing some short-run alleviation of pressure on affordability, cannot be seen as a solution to affordability challenges. Minimum expenditure levels are a floor in terms of affordability and households will need to immediately adjust back to these levels once the economy reopens. It cannot be expected that households would keep expenditure at the reduced levels for anything other than the severe public health crisis phase of the pandemic. It is more than likely that households will need to undertake these expenditures again as soon as the public health restrictions ease. Indeed, Coffey et al. (2020) point out that essential items make up a larger share of expenditure for renters. This will make renters more susceptible to income shocks as the crisis continues. These households are less likely to be able to adjust their consumption downwards in the medium term to absorb more sustained income shocks. A better assessment of the broader affordability challenges, not limited to the three months since the onset of the crisis, does not make these adjustments, and uses the figures in Table 3.6. In particular, the cost of childcare will rapidly return as households reengage with the workforce and this will stretch many households who require this service.

\section{Savings and financial buffers}

A further crucial element determining the extent to which households may be able to absorb any economic shock is the availability of savings. Households with savings may prefer to run down these savings, rather than default on rental payments and thus affect their repayment history, which could lead them to face a heightened eviction risk in the future. Recent research by O'Toole and Slaymaker (2020) shows the considerable importance of liquidity in how affordability shocks pass through to arrears in the mortgage market.

One of the limitations of the SILC dataset is that no information is available on the level of savings or the financial assets of the households. We are not therefore able to link our microsimulation estimates of the employment and resulting income shocks to the level of savings each household has. Instead, to gain insight into the levels of savings of Irish rental households, we use an alternative source of data, the Household Finance Consumption Survey (HFCS). The HFCS is a pan-European dataset containing information on households' wealth, income and other assets. This allows us to combine information on housing tenure and the value of funds held in savings accounts to get an insight into the level of liquid reserves held by Irish renter households.

A number of complications must be noted. The HFCS dataset does not contain 
information on whether households are in receipt of HAP or other housing subsidies. Nor does the survey distinguish between private renters and local authority or approved housing body tenants. We cannot therefore make a one-toone match with the sample of non-supported private renters explored in this research. Instead, using information on the distributions of gross incomes, rent levels and rent-to-gross-income ratios ${ }^{27}$ in our SILC non-supported private rental sample, we create a sample using the HFCS data that closely matches our SILC sample in terms of the distributions of these variables. See Table A.1 in Appendix 1 for a comparison of our HFCS and SILC samples.

Figure 3.4 presents the distributions of savings and savings-to-rent ratios across renter households. The median level of savings for renters is approximately €3.6k, with the median savings to rent ratio standing at 3.8. This suggests that, if the median household were to use their savings to cover their rent, they would be able to do so for just under four months. It is clear that the distribution is highly skewed, with many households having low levels of savings.

\section{FIGURE 3.4 DISTRIBUTION OF SAVINGS AND SAVINGS-TO-RENT RATIOS}

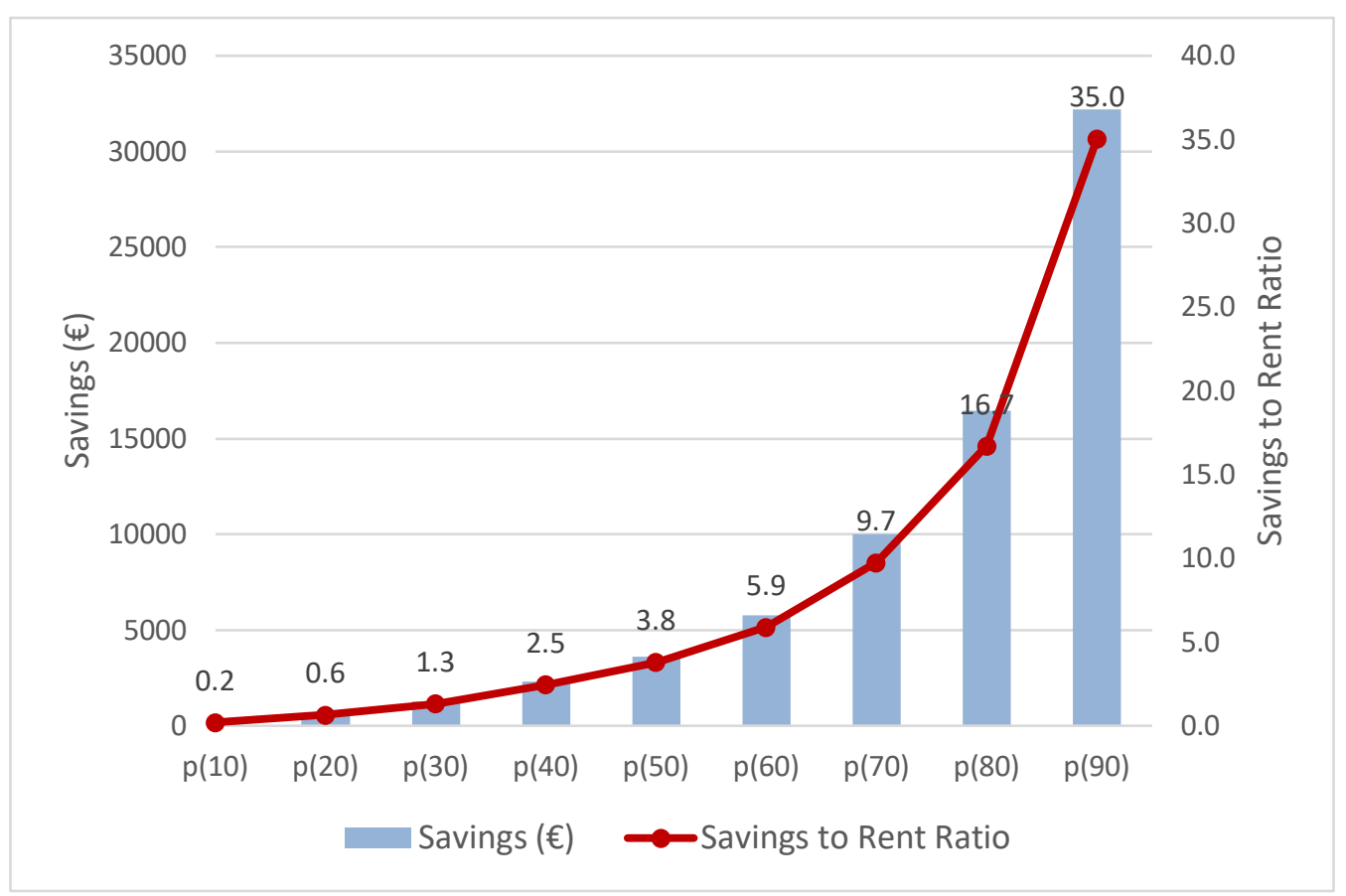

Sources: Authors' calculations using Household Finance and Consumption Survey 2018.

Figure 3.5 shows the percentage of households able to cover their rental payments for 1, 2 and 3 months. Note that this refers solely to rental payments and does not include other expenses such as household bills. Just under 74 per cent of these households are able to cover one month's rent, meaning that approximately one in four would have insufficient savings to cover even one month's rent. Approximately two-thirds can afford to cover two months' rent, and this drops to

\footnotetext{
${ }^{27}$ We use rent-to-gross-income ratios for this matching as the HFCS data do not contain net income figures.
} 
just under 58 per cent for a three-month period. It is clear that, while many households, using savings, could cover rent for some period if they need to do so, this strategy is not available to a significant portion of non-supported rental households.

\section{FIGURE 3.5 PERCENTAGE OF HOUSEHOLDS ABLE TO COVER RENT WITH SAVINGS BY NO. OF MONTHS}

Sources: Authors' calculations using HFCS 2018.

Note: This refers purely to rental payments. It does not include utilities, insurance or any other living costs. Savings refer to deposits in savings accounts.

\section{Rent Supplement as a housing cost tool}

An objective of this paper is to consider the impact of these shocks on housing affordability and on the ability of households to make rental payments. The impact of income supports such as the PUP and the TWSS have been addressed; however, there is another state income support, which pre-existed the pandemic, that is of strong relevance. Rent Supplement is a short-term, means-tested payment for people living in private rented accommodation who cannot provide for the cost of their accommodation from their own resources. ${ }^{28}$

Rent Supplement is available to households which are in receipt of other income supports, including Jobseeker's Benefit, Jobseeker's Allowance and the PUP, and to households which receive labour-market income. A means test is applied and, for the lowest-income qualifying households, the value of the Rent Supplement payment can meet much of the monthly rental payment. Qualifying conditions,

\footnotetext{
${ }^{28}$ Under the scheme, a low-income household that undergoes a substantial change in circumstances which impairs its ability to meet private market rental costs will receive income to assist making rental payments, providing certain conditions are met, including a means test and area-specific rental payment ceilings. It is important to note that the payment can be considerable; for instance, a qualifying household with income under a given threshold and which satisfies the criteria will, in many cases, have almost all of the rental payment met by Rent Supplement, aside from a minor contribution.
} 
such as habitual residence, must be met by applicant households. However, in March 2020 some of these conditions were effectively relaxed and an accommodative stance was reportedly adopted by the administrators of the scheme, with a view to ensuring that claims were processed quickly and that households in need of assistance due to the pandemic-related labour-market shock gained support. Qualifying conditions which were relaxed included the nonassessment of savings and other capital as an applicant household's means, the acceptance of claims based on limited documentation, and the suspension of the rule which prevented Rent Supplement claims if an applicant or their partner worked 30 hours or more employment per week, provided the applicant had a reduction in income due to the public health emergency.

Figure 3.6 presents published data on the take-up of the various payments. It is clear there has been a low take-up of Rent Supplement and Jobseeker's Benefit and Jobseeker's Allowance, the latter two schemes being reported together under the Live Register Payment heading. While the Pandemic Unemployment Payment explains the low take-up of the traditional Jobseeker's payments, the low take-up of Rent Supplement is surprising. This support would have a major impact on the affordability of housing costs for many renting households that have experienced pandemic-related unemployment, particularly given the measures taken to improve accessibility to the payment during the pandemic. Figure 3.6 shows that, while the employment supports increased, the growth in the numbers of Rent Supplement claims awarded has been relatively low. On 30 May 2020, the number of Rent Supplement claims awarded and in payment was 20,339, an increase of 5,403 since 29 February 2020. ${ }^{29}$

${ }^{29}$ Rent Supplement award counts provided by officials of the Department of Employment and Social Protection. 


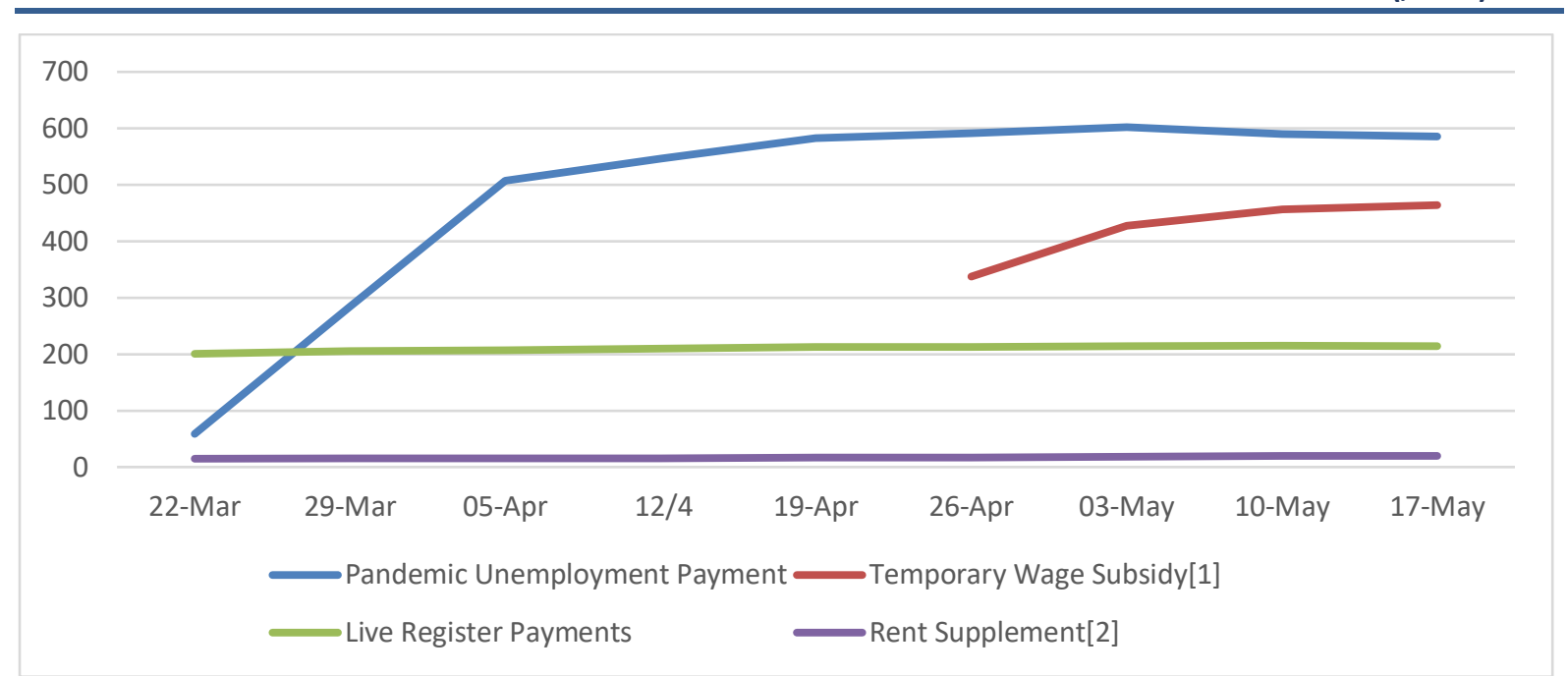

Sources: Rent Supplement award counts provided by officials of DEASP, PUP numbers from DEASP, TWSS figures from Office of the Revenue Commissioners, Live Register figures from CSO.

\section{An illustrative impact of Rent Supplement}

In this section, we attempt to illustrate how Rent Supplement could affect affordability for the households, using our microsimulation analysis. We use the qualifying criteria, as relaxed in March 2020, and apply these to the households in our sample. The Rent Supplement payment is provided in concert with the other simulated pandemic-related income supports, the PUP and TWSS. The simulation with Rent Supplement is thus an extension of the simulated impact of the PUP and TWSS. Note that this sample, by design, initially included no households in receipt of Rent Supplement, as the purpose of the paper is to examine the impact on exposed, that is non-supported, households in the private rental sector.

In this scenario, we apply the Rent Supplement payment to all eligible households in our sample. In reality, full take-up of payments by all eligible households would not likely be the case as it seems, based on published scheme uptake data and the results below, that many eligible households are either unaware of Rent Supplement or are unwilling to apply for the payment. Potentially eligible households may also be notionally aware of Rent Supplement but may choose not to apply due to a poor understanding of the scheme and the calculations used to determine payment levels, or an unwillingness to take the steps necessary ${ }^{30}$ to make an application. ${ }^{31}$

In our scenarios, eligibility for Rent Supplement has been assessed under the relaxed eligibility criteria introduced in March 2020 and based on household

\footnotetext{
${ }^{30}$ That is, to assemble and complete documents and otherwise engage with the social security apparatus.

${ }^{31}$ Calculating the potential benefit of Rent Supplement to a given household is not straightforward. Potentially eligible households with minimal experience of the social welfare system may struggle to predict whether they are eligible and, if eligible, what the level of payment may be.
} 
income after the simulated labour-market shock and the simulated assignment of the PUP and TWSS to households in our sample. It has been necessary to make several assumptions in order to assess Rent Supplement eligibility and payment levels, however. Among the more important is the treatment of households with three or more adults in what seem likely to be house-sharing arrangements. In the SILC survey microdata, housing units, such as houses or apartments composed of multiple unrelated adults, are currently classed as a single household for the purposes of estimating household income and are organised in the dataset accordingly. However, in many such instances these households are actually composed of distinct households in a given housing unit, as finances are separate and each resident is, in practice, responsible for a given proportion of the rent. Further, the division of rent among occupants may be uneven. The SILC survey microdata do not identify such shared housing units. It has been necessary to identify and subdivide them into constituent households for the purposes of Rent Supplement as, in such circumstances, Rent Supplement qualification and payment levels are calculated on the basis that separate households can and do exist within single housing units. This, in effect, results in an increase in the number of households in our sample by about 15 per cent for the purposes of simulating Rent Supplement assignment. ${ }^{32}$ This increase is composed of adults who live in a housing unit occupied by three or more adults who are not related, or in a small number of cases a housing unit of three or more adults who may be related but are not parents, children or partners of parents or children. In such instances we have assumed that the rent is divided equally among all residents of the housing unit. $^{33} 34$

Further assumptions include those used to translate net post-pandemic income into gross income, as the calculation of Rent Supplement is based on gross income, and the assumption that in all instances the rents paid by households fall below the effective local thresholds used to determine Rent Supplement eligibility. The latter assumption is necessary because it is not possible to identify the specific geographic area in which SILC households reside. ${ }^{35}$ Lastly, in households composed of parents and adult children, all of the income of the adult children has been used to determine the potential payment level of Rent Supplement, and thus the

\footnotetext{
${ }^{32}$ The proportion in the SILC survey of shared households composed of three or more adults who are not related seems, in our view, to be low. It may be the case that the sampling and survey collection methods used to collect SILC data in Ireland, in addition to the relatively dynamic nature of such households compared to other groups, such as families in owner occupation, result in a sample which potentially under-represents the prevalence of such households in the rental sector.

${ }^{33}$ It is not possible to identify couples sharing rooms, or other similar arrangements, in such shared households. ${ }^{34}$ Such 'additional' households are generally younger, with a median age of 28 . There are no children aged under 18 living in these households.

${ }^{35}$ The latter assumption is likely to hold in all but a small proportion of instances, based on the rents observed among our sample; the median rent for a housing unit in our sample is $€ 932.66$, the mean is $€ 1,042.30$. We consider that for any households for which the rent limits are breached, the estimated award of Rent Supplement is likely to be zero or relatively low, as such units seem likely to be occupied by higher-income households among our sample.
} 
payment level may be a conservative estimate in such instances.

The fourth column of Table 3.10 sets out the impact on affordability of the simulated assignment of eligible households to Rent Supplement. For the purposes of comparability, households composed of multiple sharing adults have been recombined, such that the total household income of all persons living in the housing unit is aggregated and the aggregate rent is used to determine rent-toincome ratios. The most appropriate comparison is with column three of the same table, as the Rent Supplement simulation builds on the assignment of pandemic income supports.

We estimate that in the region of two-thirds of households in our sample would receive additional income from a simulated Rent Supplement payment. These payments would have a positive impact on ratios of rent-to-net income ratio (RTI) and residual income. Among all households in our sample, including those which do not receive a simulated Rent Supplement payment, the median RTI improves as it declines from 25.9 to 23.6 , and the percentage of households with an RTI above 30 per cent declines from 32 to 24 per cent. The median monthly residual income increases from $€ 2,765$ to $€ 3,153$ and the median ISR increases to 1.40 . The percentage of households with an ISR of less than 1 is just under 27 per cent, almost 3 percentage points below the baseline scenario and 14 percentage points below the scenario in which pandemic income supports are provided without Rent Supplement.

\section{TABLE 3.10 IMPACT OF RENT SUPPLEMENT ON AFFORDABILITY OUTCOMES}

\begin{tabular}{|l|c|c|c|}
\hline & Baseline - pre-COVID-19 & $\begin{array}{c}\text { Pandemic Income } \\
\text { Supports - PUP \& TWSS }\end{array}$ & $\begin{array}{c}\text { Pandemic Income } \\
\text { Supports with Rent } \\
\text { Supplement }\end{array}$ \\
\hline Mean RTI & 25.8 & 30.1 & 24.7 \\
\hline Median RTI & 23.6 & 25.9 & 23.6 \\
\hline \% with RTI>30\% & 25.7 & 32.3 & 24.2 \\
\hline $\begin{array}{l}\text { Mean Residual income } \\
\text { (monthly) }\end{array}$ & 3461 & 2958 & 3383 \\
\hline $\begin{array}{l}\text { Median Residual } \\
\text { income (monthly) }\end{array}$ & 3224 & 2765 & 3153 \\
\hline $\begin{array}{l}\text { Mean ISR } \\
\text { Median ISR }\end{array}$ & 1.78 & & 1.74 \\
\hline \% with ISR<1 & 1.44 & 1.51 & 1.40 \\
\hline
\end{tabular}

Source: $\quad$ Authors' calculations using SILC 2018.

The analysis presented in column four of Table 3.10 is for all households in our sample of non-supported private market renters. However, in this sample, some households qualify for Rent Supplement and others do not. For those households which qualify for Rent Supplement, the median improvement in RTI is 3.5, comparing RTI for those households before and after receipt of Rent Supplement. 
For those households in the bottom quartile of the income distribution, ${ }^{36}$ the median improvement is 9.5 , which is very considerable for low to moderateincome households. Furthermore, the median increase in monthly residual income for simulated recipients of Rent Supplement is approximately $€ 520 .^{37}$

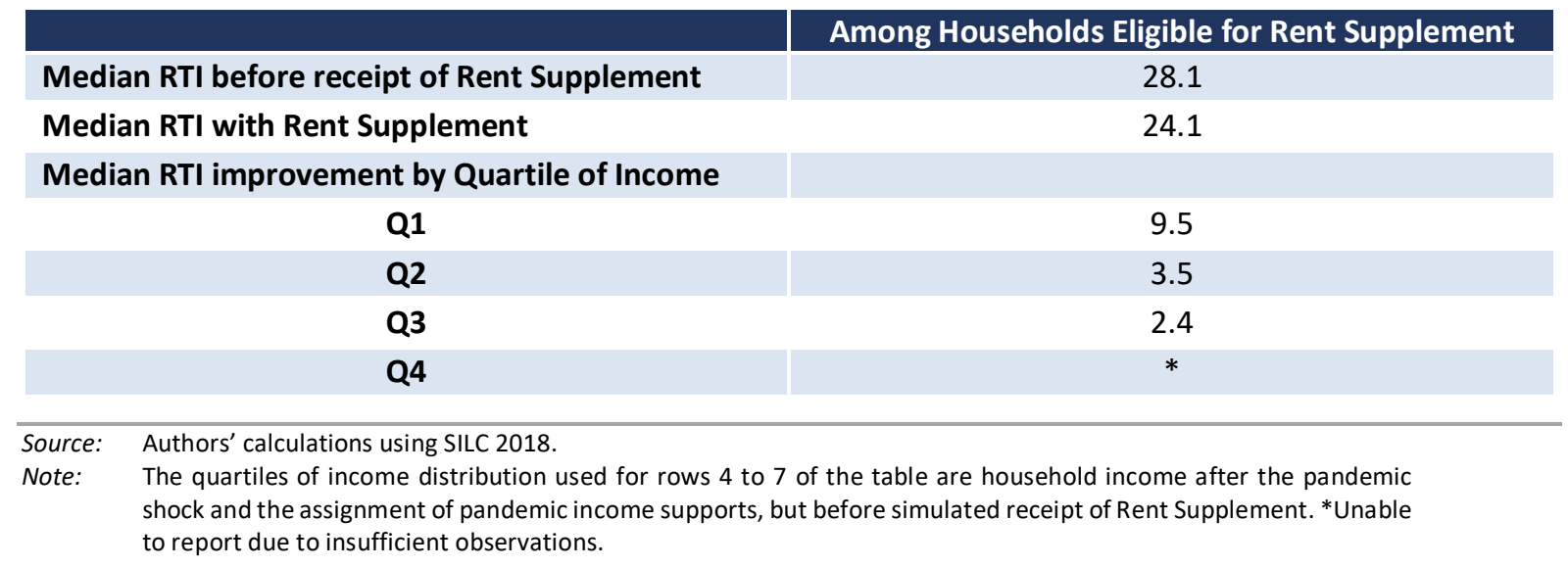

It would seem that Rent Supplement could act to considerably improve housing affordability among many households renting in the private market. However, as described above, the observed take-up of Rent Supplement during the second quarter of $\mathbf{2 0 2 0}$ was lower than may have been anticipated. Given the extreme severity of the labour-market shock, it seems that Rent Supplement could have a stronger role to play in shielding low and moderate-income households from housing affordability difficulties. ${ }^{38}$

\footnotetext{
${ }^{36}$ Anchored on the distribution of household income after the pandemic shock and the assignment of pandemic income supports, but before simulated receipt of Rent Supplement.

${ }^{37}$ As of early June, the Department of Employment and Social Protection advised that the average monthly award of Rent Supplement claims awarded after 13 March 2020 is €694. The difference may have several explanations, including selection effects that cause, for instance, the households with lowest incomes or high relative rents to apply for Rent Supplement, or could be due to the 2018 SILC sample of private market renters being less than perfectly representative of the actual 2020 cohort.

${ }^{38}$ Our analysis also suggests that, prior to the pandemic, many households that may have been eligible for Rent Supplement were not in receipt of this support. A relatively low take-up of Rent Supplement may thus be a persistent factor; exploring the levels of take-up of means-tested income and housing supports in Ireland seems to be a worthy avenue for further research.
} 


\section{CHAPTER 4}

\section{EXPLORING THE IMPACT ON MISSED PAYMENTS AND ARREARS}

As we have seen in the previous chapter, the initial period of the COVID-19 crisis is extraordinary and unique in terms of both the composition of the economic shock and impact of the public health restrictions, as well as the policy response. Indeed, as demonstrated in the previous chapter, with changes to consumption baskets, it is likely that many households may experience a short-term offset of affordability pressures during the acute phase of the pandemic (to mid-June 2020).

Given these unique and extremely time-bound circumstances, a further question arises as to how affordability developments since the onset of the crisis may translate into missed payments in the near term. Affordability in essence is a concept which relates not only to households who face acute financial difficulties but more broadly relates to their standard of living. Missed payments, on the other hand, is a situation most closely related to extreme financial difficulty.

Measuring and assessing the economic determinants of missed payments in the private rental sector is extremely difficult due to a clear data gap: there is no national, real-time measure of arrears in the rental sector. The CSO SILC survey provides an annual measure of the share of households who have missed a payment in the past 12 months, but this survey is published with a large time-lag. The absence of these data, therefore, do not allow any assessment of the actual number of missed payments that may have occurred due to the pandemic. Closing this data gap should be a priority in terms of addressing informational deficits in the rental sector. The only source of current information is a recent one-off survey on life and employment effects of the COVID-19 pandemic conducted by the CSO. It found that only 2 per cent of households indicated difficulties paying their mortgage or rent due to the COVID-19 pandemic. $^{39}$ It must be noted that this survey was conducted in the early stages of the pandemic, in April, and the situation may have changed as the pandemic has progressed.

Despite the evident data gap, in this chapter we attempt to use historical SILC data, coupled with the findings on affordability and the simulated labour-market and consumption shocks outlined in Chapter 3 , to consider the likely impact on missed payments in the rental sector. It is important to note that this analysis focuses solely on missed payments in the short-term, initial three-month period of the pandemic. 


\section{LINKING LABOUR-MARKET SHOCKS, AFFORDABILITY AND ARREARS}

\section{Measuring and modelling missed payments in the rental sector}

Measuring and modelling the determinants of arrears in the Irish mortgage market has received considerable attention in the years since the financial crisis, but little research has been undertaken on arrears in the rental sector. While this is understandable due to the financial stability implications of the major loan losses in the mortgage market, it means that few studies are available to draw on when considering missed rental payments. As noted earlier in this section, there is no current national real-time data on rental arrears which can be used to explore and determine trends.

As an alternative, we can use data on missed payments in the private rental sector from the SILC dataset to explore the determinants of, and trends in, payment difficulties in the rental sector. The SILC data captures information on whether households have missed rental payments over the past 12 months due to financial difficulties. The trend over time of the percentage of households indicating such missed payments is presented in Figure 4.1. The chart includes both those in receipt of housing supports and non-supported households. Arrears in both the private rental sector and the mortgage market show a clear cyclical component that is linked to developments in the broader economy, particularly unemployment.

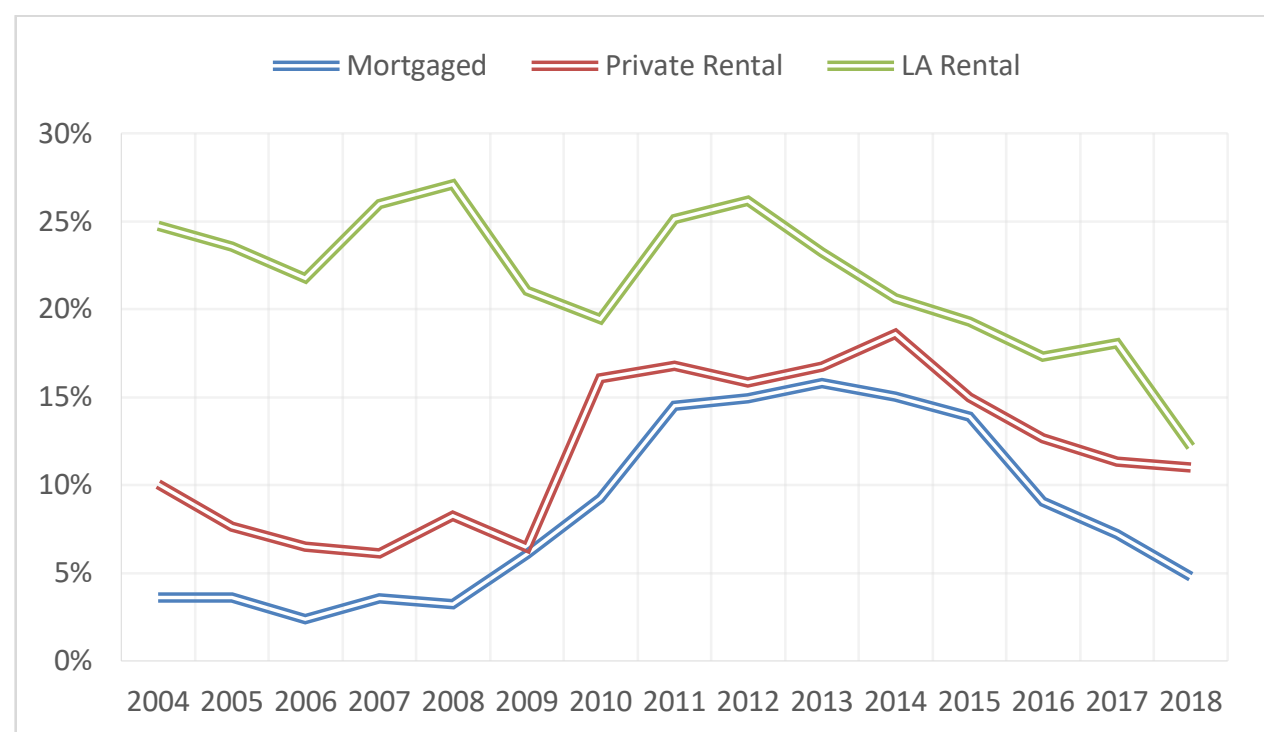

Source: SILC 2004-2018

Note: This refers to the entire private rental sector, not the subsample of non-supported private renters. 
While we are interested in understanding developments in arrears in the rental sector, the clear correlation with arrears in the mortgage market (shown in Figure 4.1), suggests that research on missed payments in the mortgage market may provide insight into understanding the private rental sector. In the mortgage literature, arrears are regularly determined as a function of the unemployment rate or other measures of affordability, both in Ireland and internationally. ${ }^{40}$ Indeed, previous research finds clear links between labour-market shocks and missed payments (Lydon and McCarthy, 2013; Kelly and O'Malley, 2016). More recent research has explicitly looked at measures of housing payment to income (the equivalent to our rent-to-income ratio) and the link with arrears (McCarthy, 2014; O'Toole and Slaymaker, 2020). These studies all find a strong role for affordability channels in determining arrears.

To explore the relationship between missed payments and affordability in more detail, we first explore the correlation between missed payments in the private rental sector and our affordability metrics. Figure 4.2A presents the correlation between missed payments and the unemployment rate over the period 20072018. It shows a clear, positive correlation between these two variables. However, the correlation between the rent-to-income ratio and missed payments in Figure $4.2 B$ is low. A stronger correlation is evident in panels $C$ and $D$, which look at the correlation between missed payments and the level of residual income after housing cost and the ISR ratio. Both of these factors show a clear negative association with missed payments; higher residual income or a higher ISR ratio are associated with a lower likelihood of missed payments. This is not to say that all households with a low ISR or residual income automatically miss payments. Indeed, approximately only one-fifth of our non-supported private rental households with a pre-COVID-19 ISR $<1$ had missed rental payments. This indicates that even those facing significant affordability stress often did not incur missed payments. However, it does point to a strong relationship between the two variables.

\footnotetext{
${ }^{40}$ Mortgage arrears stress-testing models used by the Central Bank of Ireland include aggregate (regional)
} unemployment to determine the affordability channel (Gaffney et al., 2014). 
FIGURE 4.2 CORRELATION BETWEEN MISSED PAYMENTS, AFFORDABILITY AND UNEMPLOYMENT

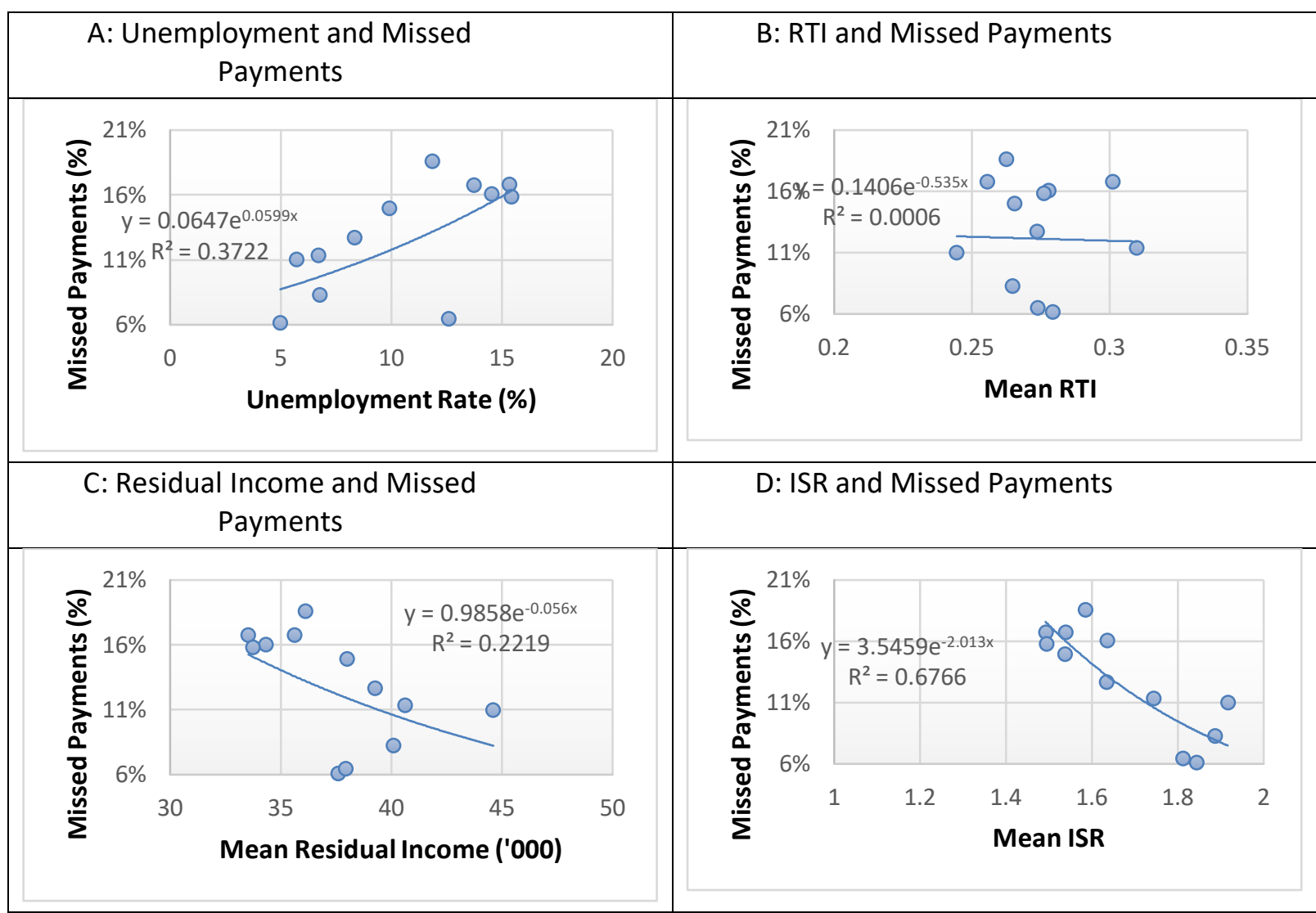

Source: $\quad$ SILC 2007-2018

Note: These figures are for the entire private rental sector, not the subsample of non-supported private renters.

To estimate the link between affordability and missed payments in the rental sector more formally, we use the SILC data to estimate a very simple pooled crosssectional missed-payments model over the period 2007 to 2017. We present a number of specifications of the model in Table 4.1. In this model, we link having missed rental payments to a measure of affordability, as well as to whether the household is unemployed and is a regular saver. The measures of affordability used are household income, household residual income, the rent-to-income ratio and the ISR respectively. Using all of these factors allows a broader understanding of the variables that are correlated with missed payments. We control for household composition, age group and NUTS3 region in all regressions.

The first thing to note from Table 4.1 is the consistent significance and magnitude of the relationship between unemployment and missed payments, regardless of the income/affordability measure included. Having an unemployed person in the household increases the chance of missed payments by approximately 7 per cent. Columns 1 and 2 show the relationship between income and missed payments (with and without unemployment). A 1 per cent increase in income is associated with a 5 per cent fall in the likelihood of missed payments. Columns 3 and 4 instead 
include residual income after rent, with similar findings. From columns 5 and 6 we see that the level of the RTI is not a statistically significant determinant of whether a household misses a rental payment. The low correlation shown in Figure 4.2B pointed towards this finding. Rather, from columns 7 and 8 , we see that it is the ISR that is a significant determinant of missed payments, with a higher ISR associated with a lower likelihood of missing rental payments. Our preferred model specification including both the ISR and unemployment is presented in column 8 .

\begin{tabular}{|c|c|c|c|c|c|c|c|c|}
\hline & (1) & (2) & (3) & (4) & (5) & (6) & (7) & (8) \\
\hline \multirow[t]{2}{*}{ Ln(Income) } & $-0.0639 * * *$ & $-0.0510 * * *$ & & & & & & \\
\hline & $(0.0108)$ & (0.0111) & & & & & & \\
\hline \multirow[t]{2}{*}{$\begin{array}{l}\text { Ln(Residual } \\
\text { Income) }\end{array}$} & & & $-0.0604 * * *$ & $-0.0483 * * *$ & & & & \\
\hline & & & $(0.0104)$ & $(0.0106)$ & & & & \\
\hline \multirow[t]{2}{*}{ RTI } & & & & & 0.0246 & 0.0203 & & \\
\hline & & & & & (0.0159) & $(0.0158)$ & & \\
\hline \multirow[t]{2}{*}{ ISR } & & & & & & & $-0.0513 * * *$ & $-0.0408 * * *$ \\
\hline & & & & & & & (0.00989) & (0.00958) \\
\hline \multirow[t]{2}{*}{ Unemployed } & & $0.0730 * * *$ & & $0.0734 * * *$ & & $0.0814^{* * *}$ & & $0.0720 * * *$ \\
\hline & & $(0.0112)$ & & $(0.0112)$ & & $(0.0111)$ & & $(0.0112)$ \\
\hline \multirow[t]{2}{*}{ Regular saver } & $-0.179 * * *$ & $-0.166 * * *$ & $-0.180 * * *$ & $-0.167 * * *$ & $-0.198 * * *$ & $-0.179 * * *$ & $-0.175 * * *$ & $-0.163^{* * *}$ \\
\hline & (0.0175) & $(0.0174)$ & $(0.0175)$ & $(0.0174)$ & $(0.0172)$ & $(0.0172)$ & (0.0175) & $(0.0174)$ \\
\hline Controls & Yes & Yes & Yes & Yes & Yes & Yes & Yes & Yes \\
\hline Observations & 6,788 & 6,788 & 6,788 & 6,788 & 6,788 & 6,788 & 6,788 & 6,788 \\
\hline
\end{tabular}

Source: $\quad$ SILC 2007-2017.

Note: $\quad$ Dependent variable $=1$ if household has missed a rental payment in the past 12 months due to financial difficulties. Controls include household composition, age group and NUTS 3 region. Average marginal effects from logit regressions reported. Standard errors in parentheses $* * * p<0.01, * * p<0.05, * p<0.1$.

\section{Scenarios for possible developments in missed payments}

Using our preferred specification (column 8 of Table 4.1), we can pass the new shocked income levels and unemployment rates from our simulations in Chapter 3 through the estimated coefficients to calculate a new predicted missed-payments rate for our sample of non-supported renters. The results of the subsequent simulations are presented in Table 4.2. The first thing to note is that using the historical coefficients from the 2007-2017 model generates a 9.8 per cent missedpayments rate in our 2018 sample of non-supported renters. This is close to the actual missed-payments rate of 10.1 per cent for that sample. Under the full pandemic income shock - i.e. not accounting for any consumption adjustment our model estimates suggest that the rate of missed payments would rise by 26.5 per cent to 12.4 per cent of households. Adjusting for consumption, this would rise by a smaller 10 per cent to 10.8 per cent of households. That the rate of missed payments still rises despite the consumption adjustment which was shown in Table 
3.9 to have reduced the proportion of households with an ISR $<1$ relative to pre-

COVID-19, highlights the importance of unemployment in the model. ${ }^{41}$

TABLE 4.2 PREDICTED MISSED PAYMENTS RATES - MODEL APPROACH

\begin{tabular}{|l|c|c|}
\hline & $\begin{array}{c}\text { Missed Payments Rate - } \\
\text { Model Approach (\%) }\end{array}$ & \% Change \\
\hline $\begin{array}{l}\text { Pre-COVID-19 Baseline } \\
\text { Income and Unemployment Shock (PUP \& }\end{array}$ & 9.8 & 26.5 \\
\hline $\begin{array}{l}\text { TWSS) } \\
\text { Income and Unemployment Shock - } \\
\text { Consumption adjustment }\end{array}$ & 12.4 & 10.2 \\
\hline
\end{tabular}

Source: Authors' calculations using SILC.

Note: $\quad$ The baseline predicted rate of arrears of $9.8 \%$ is very close to the actual observed rate of $10.1 \%$.

\section{Pandemic-related specificities: a cautionary note on the modelling scenarios}

While the above estimates provide a model-based figure, there are numerous reasons why such an estimate may not accurately capture reality in the current climate. Any parameters estimated from a historical period reflect the institutional, environmental and economic circumstances of that time. This includes the suite of policies available, in particular regarding the security of tenure and income replacement rate of social supports. The scale of the COVID-19 pandemic has been such that the whole economic and regulatory environment has changed markedly since March 2020. Thus historical inference may be highly misleading in the present context.

A number of particular factors are important in this regard. The temporary ban on evictions may change households' willingness to use absorption buffers to mitigate shocks or to continue making payments even if they are able to. This may lead to an increase in missed payments well above what is estimated in our model as the consequence of missed payments in terms of eviction is removed in the short run. While many households are likely to try to continue to maintain payments, in particular those who value the longer-term relationship with the landlord, there may be an element of strategic default which leads to higher missed payments than otherwise would be the case. This dynamic (moral hazard) has clearly been demonstrated in the mortgage market where the removal of repossession risk following the Dunne Judgement has been shown to markedly increase defaults for first-time buyers (O'Malley, 2018).

On the other hand, the fact that landlords can avail of a mortgage holiday during

\footnotetext{
${ }^{41}$ In a scenario with an income shock and pandemic consumption adjustment, but without making those receiving the PUP unemployed in the model, the missed-payments rate would fall to 9 per cent, lower than the pre-pandemic baseline. This highlights how the increase in unemployment drives the increase in the missedpayments rate in the model, in addition to any changes driven by the income shocks through the ISR.
} 
the three-month period from March may result in the number of missed payments being somewhat understated during the present period if informal, short-term arrangements are put in place. Once the mortgage holiday is over and landlords come under pressure to make repayments themselves, they are likely to pass this on to tenants, potentially resulting in increased pressure on the arrears channel. ${ }^{42}$ This highlights the exceptional nature of the reference period and why it is difficult to assess the likely rate of missed payments in the rental sector during this time.

It is also the case that this environment has been changing rapidly; initial expectations of a sharp contraction followed by a relatively rapid return to the prepandemic economic situation have changed. As expectations change, it follows that behaviour will also change, in particular households' willingness to use savings to avoid missing rental payments. If the scale of the pandemic is such that households begin to see the employment shock as extended rather than transitory, their ability and willingness to run down savings balances or continue to draw on loans from friends or family may change. This may lead to an increase in rental arrears as the scale and depth of the pandemic-related economic shock is revealed.

Furthermore, our analysis treats households in receipt of the PUP as unemployed. However, the PUP is a departure from traditional ILO measures of unemployment as it does not include any assessment of the likelihood of returning to work in the next three months. Presumably, a number of PUP recipients would have been expecting to return to work as public health measures eased and the economy reopened. These households may have had further behavioural considerations with respect to the decision of missing a payment, potentially making them different from those in the regression sample that were unemployed in the traditional sense. For this reason, our estimate should be seen as applying an unemployment shock which represents an upper bound to the level of the unemployment rate (not to the missed payments predictions).

In conclusion, while our analysis focuses solely on the immediate, short-run time frame, it is likely that the scale of the COVID-19 shock is such that, the longer the duration of the downturn, the higher the missed payments, and consequently, arrears rate will climb. This likelihood is magnified if the PUP or TWSS payments are withdrawn or are modified such that the effective rates of payment are considerably reduced. It also seems highly likely that the estimates presented in Table 4.2 are subject to considerable uncertainty, and many factors specific to this crisis could adversely change the missed payments rate. The removal of eviction risk and the scale of the affordability shock is likely to mean that higher rates of missed payments and a build-up of arrears are likely to occur as the economic shock begins to become ingrained.

42 Indeed with payment breaks (mortgage holidays) landlords must repay the balance with accrued interest. 


\section{MANAGING ARREARS}

For those households that do build up missed payments and experience arrears, any mitigation strategies to deal with the repayment of these balances will need to be cognisant of the specificities of the pandemic-related environment. This includes the difficulty of finding alternative accommodation, the ongoing financial challenges these households may face, and any public health advice on economic and social restrictions. In these cases, it may be necessary for forbearance strategies to be put in place in the short term. It was entirely appropriate that eviction risk was removed from households during the extreme public health phase of the crisis when households were forced to remain in place. This mechanism to ensure households are not evicted should continue in line with public health advice. However, as the economy reopens, and the recovery phase begins, these factors must be weighed off against the legal obligation to make rental payments under the tenancy contract.

For cases where missed payments have occurred, and a strategy is being designed to manage the repayment of the outstanding balance, ensuring that the repayment burden on households is affordable is critical. This repayment must take into consideration both the arrears balance to work down and the ongoing rental payment level. While there are many differences with the mortgage market, where widescale and extensive mortgage modification has been the norm in recent years, the probability of repayment has been shown to be much greater if the arrears balance and the new payment on the modified loan are set to be sustainable given the household's characteristics. McCann (2017) shows an improved payment record for loans with permanent modifications. Solutions to deal with arrears should have the flexibility to be idiosyncratic and take into consideration the caseby-case specificities of the tenant's circumstances. It may also be the case that, in some cases, an extended period may be required for arrears to be cleared; such extended periods would require good-faith engagement by tenants and landlords throughout.

The use of independent financial advisors to set the repayment burden (which includes the repayment level and the term) with reference to the circumstances may be warranted, particularly as a given landlord is unlikely to have access to a tenant's financial information. Since households that have entered arrears may find it difficult to re-enter the labour market and to generate sufficient income to clear arrears, any repayment strategy must allow for a sustainable solution that is specific to the case. This must balance the tenant's financial position with the contractual obligation towards repayment. Consideration would have to be given to the financial position of landlords, particularly those with high ongoing costs such as mortgage repayments. It is not within the scope of this research to propose, or review, the legal or institutional structures around how best to manage arrears. Rather, the aim here is to highlight the evidence that repayment works 
best if the economic cost is made sustainable for the tenant. Further work would be required to identify any legal or institutional changes this implies.

Given the moral hazard issues that may arise, the potential that in some instances the process could be lengthy, and the legal requirements which pertain to data protection and privacy, it seems likely that a neutral and expert third party will be necessary in many cases. In this regard, it may be appropriate for an independent body, such as the Residential Tenancies Board (RTB), to act as neutral arbiter for cases of arrears resolution. For renters who are experiencing financial difficulty, access to financial advice through agencies such as the Money Advice and Budgeting Service (MABS) could be beneficial.

It is also important to consider the supply-side impacts of any new mechanisms established to address widespread arrears, especially if such mechanisms inadvertently increase perceptions of the costs or risks associated with acting as a residential landlord. In a supply-constrained sector, it seems prudent to ensure that disincentives to enter or remain in the market are not created.

\section{ADDRESSING DATA GAPS}

It is clear that a major gap exists in the current data architecture in terms of measuring and monitoring arrears in the rental sector. At present, no real-time, national statistical series is available to measure the number of arrears cases and the balance of outstanding payments in Ireland. This is a major difficulty in trying to assess the prevalence of payment difficulties. The benefit of having such an indicator would have both demand-side and supply-side elements. On the demand side, it would provide an early warning system for policymakers and stakeholders of emerging financial distress among households and be better able to understand how arrears may change as the economy developments. On the supply side, it would allow investors into the market to better understand the level of payment risk, thus determining the risk-return of any investments.

In the mortgage market, the Central Bank publishes regular, timely arrears rates on mortgages, both in terms of the number of loans in arrears and the balance of arrears outstanding, while loan-level microdata provided to the $\mathrm{CBI}$ allow detailed and comprehensive research be undertaken to assess vulnerabilities of mortgages and the level of arrears.

While this is a data gap that should be filled, there are several challenges in attempting to develop such a comprehensive suite of indicators and datasets for the rental sector. First, the heterogenous nature of the sector, with many small landlords, makes submission of any data by landlords on arrears of their tenants more challenging. For example, mortgage lenders submit data to the Central Bank covering thousands of their customers in one submission. Each landlord would 
need to submit individual arrears notifications, which would be more burdensome. For some landlords, the opportunity cost of undertaking this may be prohibitive, especially if the tenancy has ended (or is likely to end) and a new tenant is in place. Second, no annual registry of tenancies is currently in place to calculate the total stock of active tenancies. While it is envisaged that this will be operational soon, until this is the case, it is not possible to accurately measure how many rental agreements are in place, which would be needed to measure the proportion of arrears.

Ideally, such a monitoring exercise would provide a requirement on all landlords to register arrears. Arrears could be defined as cases of three missed payments (consecutive or cumulatively summed over a time-bound horizon) to ensure reporting of cases where single missed payments due to exceptional circumstances are not necessary. These data could be then linked to the annual registry data on the tenant and tenancy record. It would be possible then to measure the share of total tenancies that are in arrears over a given quarter. To capture the balance of the arrears, this could be either submitted by the landlord or measured by the number of months' missed payments and the registered payment data on the annual register. It is not envisaged that these data would be used for individual dispute resolution, but rather for rental sector monitoring purposes only. 


\section{CHAPTER 5}

\section{Conclusions and Policy Implications}

The goal of this paper has been to explore some of the immediate impacts of the COVID-19 pandemic on the rental sector, with a particular focus on the initial three months of the pandemic. Our focus has been on a specific subset of the private rental sector that prior to the pandemic received no state subsidies or support towards their rental payments. We denote these households as non-supported private renters. Many of these households are likely to be vulnerable to affordability stress given the high rents they pay. We estimate that, before the pandemic, approximately one in four of these households spent more than 30 per cent of their net income on rent while nearly one in three of these households had insufficient income to cover a minimum essential standard of living after rental payments.

In terms of what has happened since the onset of the pandemic, a number of findings arise from our analysis. The labour-market shock from the COVID-19 pandemic has disproportionately affected non-supported private renters whose employment has been concentrated in sectors such as accommodation and hospitability that have been among the hardest hit. Overall incomes have fallen by nearly 9 per cent on average for the group of non-supported private renters. Given the demographic and sectoral structure of renters' employment, this is a greater decrease than for the broader population at large. If the income shock alone is accounted for, the share of households whose net income would be insufficient to cover the standard essential basket of goods and services is estimated to increase to over 40 per cent, taking account of the pandemic-related income supports.

However, the extraordinary and unique set of circumstances which have prevailed since the onset of the pandemic are likely to provide an offset to the income shock in the form of a temporary lowering of required non-housing expenditure. The extensive public health restrictions that were introduced throughout March 2020, as well as changes in households' own choices, are likely to have reduced expenditure by more than the change in income in the immediate term. Our simulations suggest that these consumption changes currently outweigh the falls in incomes overall, thus lowering short-term affordability pressures for many households.

However, this situation is likely to unwind quickly as households engage in more normal levels of expenditure, in particular on childcare and transport. Indeed, households may have postponed consumption (i.e. where items may have depreciated or need replacement) rather than completely forgone the expenditure. These items will need to be purchased in future, which may increase the expenditure requirements after the public health emergency phase, putting further financial pressure on households. While the overall economy may recover 
somewhat over the short to medium term, it is likely that there will be a relatively high level of unemployment over this period. Consequently, many in the rental sector will continue to face significant affordability challenges. In that regard, the continuation of income supports, and increased uptake of Rent Supplement, will be of particular importance to help renters during the phase of recovery from the pandemic. Research should be undertaken that takes a longer-term view of affordability pressures in the rental sector and the COVID-19 pandemic.

Given the unprecedented nature of the pandemic, it is very difficult to estimate the trajectory of the likely rate of missed payments using historical relationships. Historically, we show that unemployment has been a key determinant of missed rental payments for the private rental sector. Modelling analysis based on the relationship between affordability stress, unemployment and rental payment difficulties suggests that there is likely to be an increase in missed payments due to the income and particularly unemployment shocks faced by certain households. However, this increase in missed payments is likely to be tempered in the short run due to consumption expenditure falling more rapidly than incomes, which reduces the likelihood of arrears for many households for the period under consideration in this study. It is also important to note that emergency-related changes to regulations, such as the removal of eviction risk, or any behavioural changes that may occur due to the specificities of the pandemic may affect the rate of missed payments and subsequent build-up of arrears. It is not possible to incorporate these factors into the modelling framework used in this analysis.

One clear finding from this study is a clear data gap in the rental sector in terms of understanding and measuring arrears. No real-time indicator of rental arrears (in terms of the number of arrears cases and the value of missed payments) is available as an equivalent to the quarterly indicator published by the Central Bank in the mortgage market. At present the only national indicator of arrears is in the SILC data, which is available at a lag of two years between the reporting and the date of measurement. This indicator, which we have used in our analysis, also only provides a measure of whether households have missed a payment in the past 12 months due to financial pressures. We have therefore not been able to make any assessment of the value of arrears (in euro terms) that may have built up at the household level. While these data provide an excellent understanding of the sector and allow linkages with income and other household characteristics in a historical context, they do not allow real-time analysis of the sector, in particular in fastmoving situations such as the current pandemic. Addressing this data gap would be a very important step forward, although a practical solution may be extremely problematic given the fragmented nature of the private rental sector. 


\section{REFERENCES}

Ahrens, A., Martinez-Cillero, M., O'Toole, C. (2019a). Trends in rental price inflation and the introduction of rent pressure zones in Ireland, Residential Tenancies Board.

https://onestopshop.rtb.ie/images/uploads/Comms\%20and\%20Research/Trends _in_Rental_Price_Inflation_and_the_Introduction_of_RPZs_in_Ireland.pdf

Ahrens, A., Martinez-Cillero, M., O'Toole, C. (2019b). Price regulation, inflation, and nominal rigidity in housing rents, ESRI Working Paper 648.

www.esri.ie/publications/price-regulation-inflation-and-nominal-rigidity-in-

housing-rents

Allen-Coghlan, M., Coffey, C., McQuinn, K., O’Toole., C. (2020). Quarterly Economic Commentary, Summer 2020, ESRI.

https://doi.org/10.26504/qec2020sum

Byrne, S., Coates, D., Enda, E., Mclndoe-Calder, T., Corcoran, D., Cronin, H., Brioscú, A. (2020). The Initial Impacts of the COVID-19 Pandemic on Ireland's Labour Market, IGEES Working Paper.

www.igees.gov.ie/wp-

content/uploads/2020/05/LMAC_Working_Paper_FINAL_IGEES-pdf.pdf

Central Bank of Ireland (2020). Quarterly Bulletin, No. 2, April 2020.

www.centralbank.ie/publication/quarterly-bulletins/quarterly-bulletin-q2-2020

Central Statistics Office (2020a). Employment and Life Effects of COVID-19, April 2020.

https://www.cso.ie/en/releasesandpublications/er/elec19/employmentandlifeeff ectsofCOVID-19/

Central Statistics Office (CSO) (2020b). Detailed COVID-19 Income Support and Live Register Tables, published online, available at:

www.cso.ie/en/statistics/labourmarket/liveregister/detailedcovid-

19incomesupportandliveregistertables/

Central Statistics Office (2020c). Monthly Unemployment Statistical Release, May 2020. www.cso.ie/en/releasesandpublications/er/mue/monthlyunemploymentapril2020/

Coffey, C., Doorley, K., O'Toole, C., Roantree, B. (2020). The effect of the COVID-19 pandemic on consumption and indirect tax in Ireland, ESRI Budget Perspectives 2021 Paper 3.

https://doi.org/10.26504/bp202103.pdf

Corrigan, E., Foley, D., McQuinn, K., O'Toole, C., Slaymaker, R. (2019). Exploring Affordability in the Irish Housing Market, The Economic and Social Review, 50(1), pp. 119-157.

www.esr.ie/article/view/1121

Department of Employment Affairs and Social Protection (DEASP) (2020). Update on Payments Awarded for COVID-19 Pandemic Unemployment Payment and Enhanced Illness Benefit - Statistics, published online, available at: www.gov.ie/en/publication/f4c60c-covid-19-statistics/ 
Gaffney, E., Kelly, R., McCann, F. (2014). A Transitions-Based Framework for Estimating Expected Credit Losses, Central Bank of Ireland, Research Technical Papers No. 16/RT/14.

https://centralbank.ie/docs/default-source/publications/research-technicalpapers/research-technical-paper-16rt14.pdf?sfvrsn=8

Gerardi, K., Herkenhoff, K. F., Ohanian, L. E., Willen, P. S. (2017). Can't pay or won't pay? unemployment, negative equity, and strategic default, The Review of Financial Studies, 31(3), 1098-1131.

https://doi.org/10.1093/rfs/hhx115

Government of Ireland (2020). Guidance Document on COVID-19 Supports for Landlords and Tenants.

www.housing.gov.ie/sites/default/files/publications/files/guidance_document_s upport_for_landlords_and_tenants.pdf

Kelly, R., McCann, F., (2016). Some defaults are deeper than others: Understanding longterm mortgage arrears, Journal of Banking \& Finance, 72(C), 15-27. https://doi.org/10.1016/j.jbankfin.2016.07.006

Kelly, R., O'Malley, T. (2016). The Good, the Bad and the Impaired: A Credit Risk Model of the Irish Mortgage Market, Journal of Financial Stability, 22(C), 1-9.

https://doi.org/10.1016/j.jfs.2015.09.005

Lydon, R., McCarthy, Y. (2013). What Lies Beneath? Understanding Recent Trends in Irish Mortgage Arrears, The Economic and Social Review, 44(1), pp.117-150.

Mac Mahon, B, Thornton, R, and McEvoy, O. (2019). Minimum Essential Standard of Living 2019 Update Report, The Vincentian Partnership for Social Justice.

McCann, F. (2017). Mortgage Modifications in Ireland: a Recent History, Central Bank of Ireland, Economic Letters No. 16/EL/17.

www.centralbank.ie/docs/default-source/publications/economic-letters/vol-

2017-no-16---mortgage-modification-in-ireland-a-recent-history-

(mccann).pdf?sfvrsn=7

McCarthy, Y. (2014). Disentangling the mortgage arrears crisis: The role of the labour market, income volatility and housing equity, Central Bank of Ireland, Research Technical Papers No. 02/RT/14.

https://centralbank.ie/docs/default-source/publications/research-technical-

papers/research-technical-paper-02rt14.pdf?sfvrsn=8

O'Malley, T. (2018). Did the Dunne Judgment Lead to More Mortgage Defaults?, Central Bank of Ireland, Economic Letter Series, Vol 2018 No. 1.

www.centralbank.ie/docs/default-source/publications/economic-

letters/vol.2018-no.1---did-the-dunne-judgement-lead-to-more-mortgage-

defaults-

(o'malley).pdf?sfvrsn=4\#: :text=Did\%20the\%20Dunne\%20Judgment\%20Lead\%20 to\%20More\%20Mortgage\%20Defaults\%3F\&text=Borrowers\%20who\%20respond ed\%20by\%20defaulting,and\%20face\%20higher\%20interest\%20rates.

O'Toole, C., Slaymaker, R. (2020). Repayment capacity, debt service ratios and mortgage default: An exploration in crisis and non-crisis periods, ESRI Working Paper 652. 
www.esri.ie/publications/repayment-capacity-debt-service-ratios-and-mortgagedefault-an-exploration-in-crisis

Quigley, J.M., Raphael, S. (2004). Is Housing Unaffordable? Why Isn't It More Affordable?, Journal of Economic Perspectives, American Economic Association, vol. 18(1), pages 191-214, Winter.

https://doi.org/10.1257/089533004773563494

Revenue Commissioners (2020). COVID-19 Temporary Wage Subsidy Scheme Preliminary Statistics (as at 14 May 2020), published online, available at: www.revenue.ie/en/corporate/information-about-revenue/statistics/number-oftaxpayers-and-returns/covid-19-wage-subsidy-scheme-statistics.aspx.

Roantree, B. (2020). Job Loss Distribution (Box 3), Quarterly Economic Commentary, Summer 2020, ESRI.

https://doi.org/10.26504/qec2020sum 


\section{APPENDIX 1: ADDITIONAL TABLES}

TABLE A.1

SILC AND HFCS PRIVATE RENTAL SAMPLE MATCHING COMPARISON

\begin{tabular}{|c|c|c|c|c|c|c|}
\hline & \multicolumn{2}{|c|}{ Gross Income } & \multicolumn{2}{|c|}{ Rent } & \multicolumn{2}{|c|}{ Rent to Gross Income } \\
\hline & SILC & HFCS & SILC & HFCS & SILC & HFCS \\
\hline$p(10)$ & 24182 & 30020 & 400 & 486 & 10.6 & 9.7 \\
\hline$p(25)$ & 40279 & 39196 & 600 & 600 & 13.9 & 13.0 \\
\hline$p(50)$ & 53408 & 52340 & 850 & 800 & 18.9 & 18.8 \\
\hline$p(75)$ & 77641 & 74360 & 1200 & 1200 & 24.7 & 27.4 \\
\hline$p(90)$ & 122037 & 115180 & 1650 & 1680 & 35.7 & 36.9 \\
\hline
\end{tabular}

Source: $\quad$ SILC 2018 and HFCS 2018.

Note: $\quad$ The sample matching process was done prior to rent, income and savings variables being uprated to 201904 values. The statistics reported above are therefore based on the original reported values and have not been uprated to 201904 values.

\section{APPENDIX 2: RENTAL PRICE NOWCASTING}

A critical aspect of this study is nowcasting the rental data to represent the affordability picture at the end of 2019, as close as we can get to the onset period of the COVID-19 pandemic. This requires a set of inflation factors with which to grow forward rent levels. Normally, the selection of these uprating factors would be done by selecting a national benchmark and tying the growth to this (as we have done with the social transfers and the consumer price index). However, neither of the existing national series (RTB/ESRI rent index or the CSO rent inflation series) provides sufficient comparators, with the RTB/ESRI index only covering new rental agreements and the CSO data covering only the national picture. For our sample, we need a comparative inflation factor that covers the growth rate on new and existing tenancies, with a regional breakdown.

To obtain such a series, we revisit the dataset presented in Ahrens et al. (2019, a;b) which uses a property-matched sample of the RTB data. This sample, by linking the properties by address allows us to develop an index that captures the individual growth rates at the property level. This allows us to then measure rental growth of both new and renewal tenancies from the RTB data for the same property.

A further complication is the fact that the growth-rate distribution for rental prices faced by households is not normal and has two distinguishing features: 1) a large number of the rents in the property sample do not change over time (nominal rigidity, and is approximately 20 per cent on average across 2018/2019); and 2) there is a very long right tail on the distribution. This can be seen in Figure A.1. 


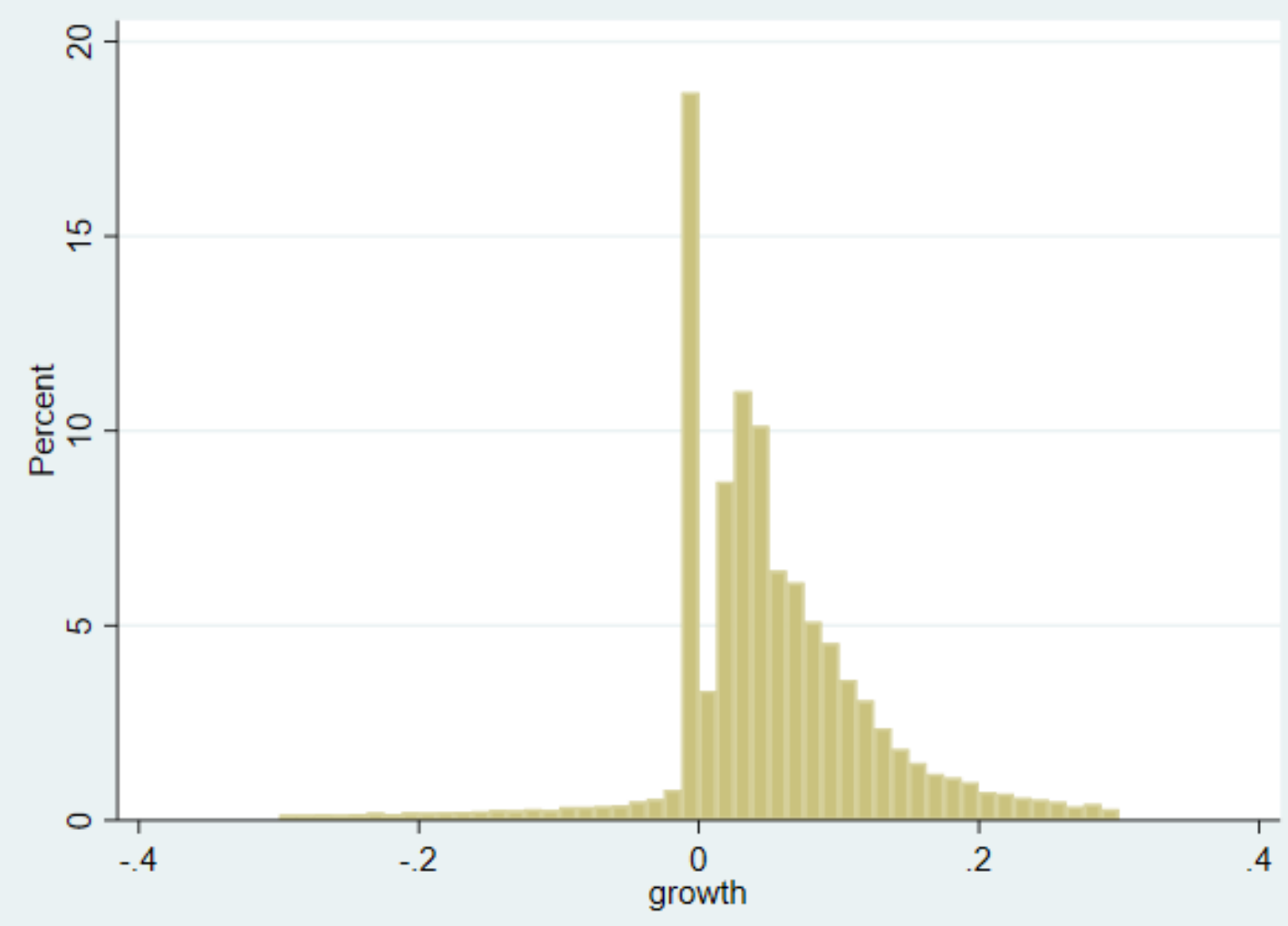

Sources: ESRI analysis of RTB data.

Note: $\quad$ Censored at $+/-30$ per cent growth for ease of readability.

Both of these distributional features lead to a major difference between the average rental price growth and the median value. To address these factors, we have chosen the median figures, which give a better distributional representation. We have therefore used the NUTS 3 regional median values from this data to nowcast our rental figures forward to 2019Q4. These data are presented in Table A.2.

TABLE A.2 MEDIAN RENTAL GROWTH BY NUTS3 REGION 2018 AND 2019

\begin{tabular}{|l|c|c|}
\hline \multicolumn{1}{c|}{ NUTS3 Region } & $\mathbf{2 0 1 8}(\mathbf{\%})$ & $\mathbf{2 0 1 9}(\mathbf{\%})$ \\
\hline Border & 3.5 & 3.0 \\
\hline Midlands & 5.9 & 5.6 \\
\hline West & 3.8 & 3.8 \\
\hline Dublin & 4.0 & 3.7 \\
\hline Mid-East & 5.1 & 4.4 \\
\hline Mid-West & 5.0 & 5.1 \\
\hline South-East & 4.7 & 5.1 \\
\hline South-West & 3.9 & 3.9 \\
\hline
\end{tabular}


Whitaker Square,

Sir John Rogerson's Quay, Dublin 2

Telephone +35318632000

Email admin@esri.ie

Web www.esri.ie

Twitter @ESRIDublin

ISBN 978-0-7070-0534-8 